INL/EXT-13- 28226

Revision 1

\title{
Evaluation of Revised Computer-Based Procedure System Prototype
}

Johanna Oxstrand Katya Le Blanc Cheradan Fikstad

January 2013

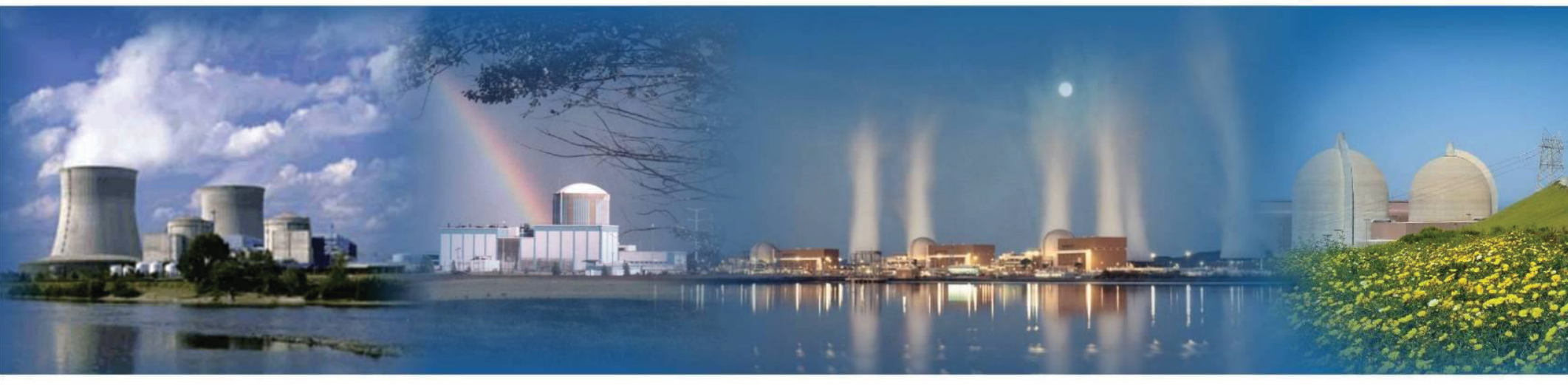

The INL is a U.S. Department of Energy National Laboratory operated by Battelle Energy Alliance 


\section{DISCLAIMER}

This information was prepared as an account of work sponsored by an agency of the U.S. Government. Neither the U.S. Government nor any agency thereof, nor any of their employees, makes any warranty, expressed or implied, or assumes any legal liability or responsibility for the accuracy, completeness, or usefulness, of any information, apparatus, product, or process disclosed, or represents that its use would not infringe privately owned rights. References herein to any specific commercial product, process, or service by trade name, trade mark, manufacturer, or otherwise, does not necessarily constitute or imply its endorsement, recommendation, or favoring by the U.S. Government or any agency thereof. The views and opinions of authors expressed herein do not necessarily state or reflect those of the U.S. Government or any agency thereof. 
INL/EXT-13-28226

Revision 1

\section{Evaluation of Revised Computer-Based Procedure System Prototype}

Johanna Oxstrand, Katya Le Blanc, and Cheradan Fikstad

January 2013

Idaho National Laboratory

Idaho Falls, Idaho 83415

http://www.inl.gov

Prepared for the U.S. Department of Energy Office of Nuclear Energy Under DOE Idaho Operations Office

Contract DE-AC07-05ID14517 



\title{
Evaluation of Revised Computer-Based Procedure System Prototype
}

\author{
INL/EXT-13-28226
}

January 2013

Approved by:

Name

Date

Title [optional]

Name

Date

Title [optional]

Name

Title [optional]

Name

Date 



\section{EXECUTIVE SUMMARY}

The Computer-Based Procedure (CBP) research effort is a part of the LightWater Reactor Sustainability (LWRS) Program, which is a research and development (R\&D) program sponsored by Department of Energy (DOE) and performed in close collaboration with industry $R \& D$ programs that provides the technical foundations for licensing and managing the long-term, safe, and economical operation of current nuclear power plants. One of the primary missions of the LWRS program is to help the U.S. nuclear industry adopt new technologies and engineering solutions that facilitate the continued safe operation of the plants and extension of the current operating licenses.

The nuclear power industry is highly proceduralized, i.e. almost all activities that take place at a nuclear power plant are conducted by following procedures. The paper-based procedures (PBPs) currently used by the industry have a demonstrated history of ensuring the safety of the industry. Despite the safety record of the current practice there is room for improvement in the use of procedures. The industry can increase their efficiency and safety by taking advantage of technological advancements, such as replacing the PBPs with Computer-Based Procedures (CBPs) that increase usability and allow human performance aspects to be integrated into the procedure. CBPs offer the option to move towards a more dynamic nature of how procedures are presented to the user. For example, the CBP system can display only the relevant steps based on operating mode, plant status, and task at hand.

The incorporation of advanced technology, such as CBP systems, may help to manage the effects of aging systems, structures, and components. Additionally, the introduction of advanced technology may also make the existing light-water reactor fleet more attractive to the future workforce.

The long-term goal for the present research effort is to develop guidance the nuclear industry can use in their discussions with potential CBP system vendors. The guidance will primarily focus on how to best design the graphical user interface, as well as the underlying data structure. The path towards the long-term goal is an iterative process where the human factors issues related to CBP usage are systematically addressed and evaluated. This research effort is focused on how to improve the efficiency, productivity, and safety of procedure usage by employing CBPs instead of PBPs.

To date three major research activities have been conducted; one qualitative study and two iterations of development and evaluation of a CBP prototype. The results from the qualitative study (Oxstrand \& Le Blanc, 2012) and the first iteration of the CBP prototype (Oxstrand, Le Blanc, \& Hays, 2012) informed the design decisions made when revising the prototype. The purpose of the second evaluation study was to evaluate whether the modification improved usability of the prototype. The study was conducted in functioning flow-loop training facility at a nuclear power plant. Ten employees at the nuclear power plant participated in this study. Nine were field operators and one was a training manager.

Compared to the first study, a more complex procedure and scenario was selected for the second evaluation study. The features that contributed to the increased complexity in the scenario chosen for this study include the presence of multiple conditional statements and branching to other procedures. These 
features of the procedure and scenario allowed the research team to better assess the impact of context sensitivity in the CBP prototype.

The main factor in this study was the procedure presentation style (PBP or $\mathrm{CBP}$ ) and it was manipulated within participants. Participants completed the scenario once with the CBP and once with the PBP (order was counterbalanced). To assess whether the CBP provided performance advantages the researchers measured completion time and deviations from the optimal procedure path. Researchers also used the NASA Task Load Index (TLX) assessment tool (Hart $\&$ Staveland, 1988) to assess the workload associated with using the CBP prototype compared with the traditional PBPs. Usability surveys were used to assess the interface of the CBP prototype and the usability of the handheld device (in this case, the iPod). Researchers also developed a debrief questionnaire to gain more detailed feedback on the design of the user interface and the overall experience using the CBP. Participation in the evaluation study was conducted in two sessions. During the first session, the participants were familiarized with the task and trained on how to use the CBP prototype. During the second session, participants executed the scenario with the CBP and with the PBP.

Executing the scenario with the CBP reduced the total number of deviations in the optimal procedure path compared to PBPs, indicating that CBPs may enhance performance. It took longer to execute the scenario with the CBP than with the PBP, which may be an artifact of the operator's unfamiliarity with the CBP prototype (compared with years of using paper-based procedures). The participants' subjective judgments of the CBP were overwhelmingly positive. The majority of participants reported that they preferred the CBP over the PBP and that they preferred the context-sensitive presentation of the procedure in the CBP over the static CPB. The workload was not significantly different between the BCP and PBP execution of the scenario.

The results of this research indicate that CBPs may be useful in preventing errors, and that operators are likely to readily accept new technology if the user interface is designed with sound human-factors principles. The researchers also gained a large amount of suggestions on how to improve the user interface that will be incorporated into a third and final version of CBP prototype for field workers. 


\section{ACKNOWLEDMENTS}

The authors would like to express special gratitude to the following people for their collaboration and support of this research effort. Thomas Waicosky, Catawba Nuclear Station, for his support in the process of identifying requirements, prototype development, and for hosting the evaluation study conducted in November 2012. Gregory Robison, Duke Energy, for being an important advocate for the research effort.

The research team also wants to extend its gratitude to all the participants and others involved in the successful execution of the November 2012 evaluation study. 


\section{CONTENTS}

ACKNOWLEDMENTS vii

ACRONYMS xi

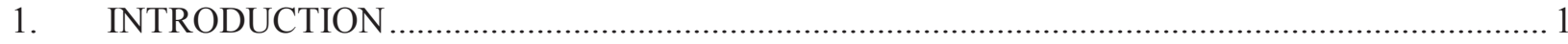

1.1 Background - Previous Research Activities ............................................................... 2

1.1.1 Characterization of Procedure Usage ....................................................................... 3

1.1.2 Model Development and Identification of Requirements for CBPs ......................... 3

1.1.3 Study 1: Development and Evaluation of a CBP Prototype......................................... 4

2. STUDY 2: EVALUATION OF REVISED CBP PROTOTYPE ……......................................... 5

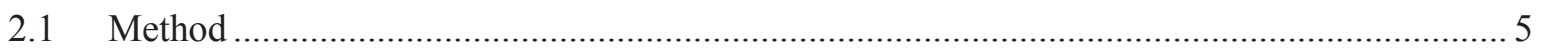

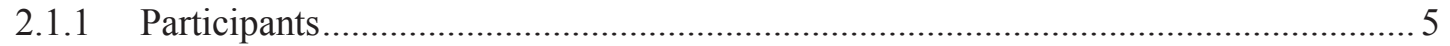

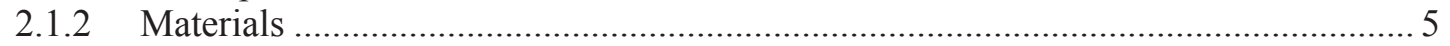

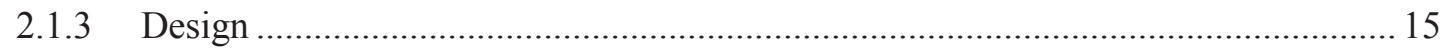

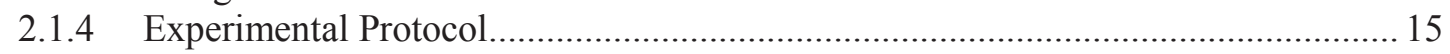

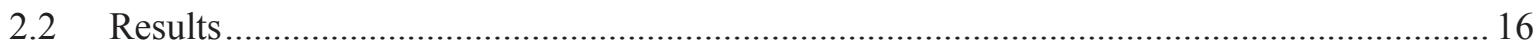

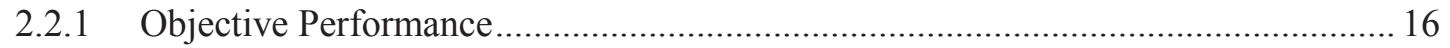

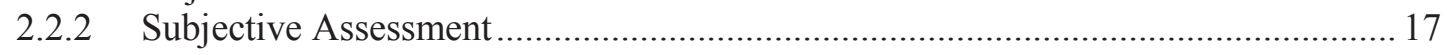

2.2.3 Comparisons with Previous Studies.......................................................................... 19

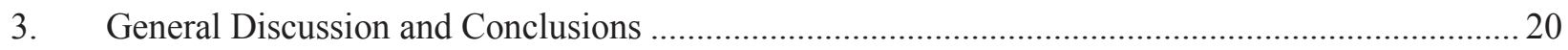

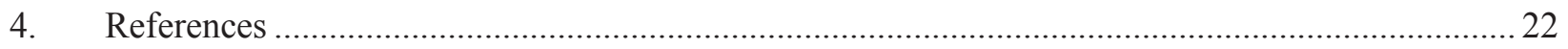

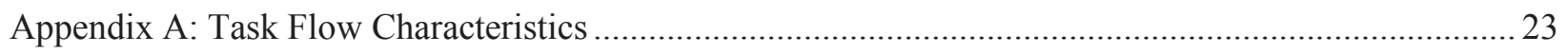

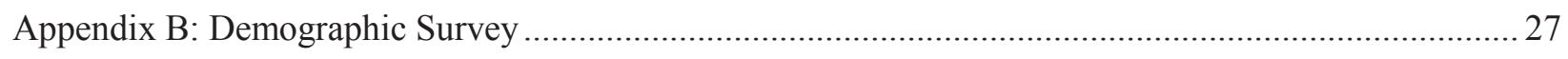

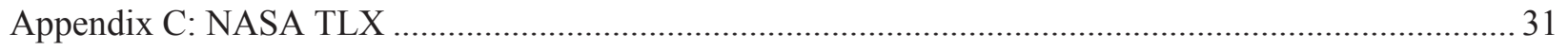

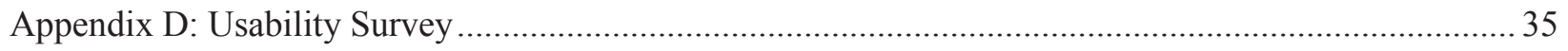

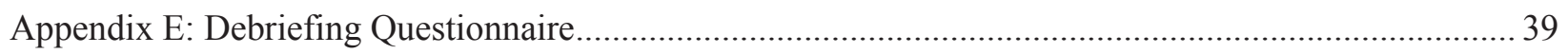

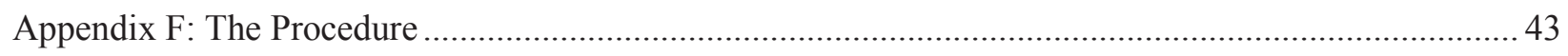

\section{FIGURES}

Figure 1 - Research Activities Conducted To Date .................................................................................. 3

Figure 2 - The Presentation Of The Active Step In The Two CBP Prototypes ......................................... 6

Figure 3 - The Overview In The Initial And The Revised CBP Prototype .............................................. 8

Figure 4 - The Difference Between Step To Be Performed And Not Applicable Steps ............................ 9

Figure 5 - The Presentation Of A Caution In The Revised CBP Interface ................................................ 10

Figure 6 - Context Sensitivity In The Initial CBP Prototype ................................................................. 11 
Figure 7 - Decision Made Based On Information Shared In The Pre-Job Brief...................................... 12

Figure 8 - System Response When Incorrect Component Is Scanned.................................................... 13

Figure 9 - Example Of Substeps That Can Be Executed Out Of Sequence And How To Record

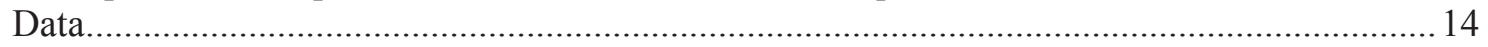

Figure 10 - Completion Time By Presentation Style …….................................................................. 16

Figure 11 - Number Of Recorded Errors By Presentation Style........................................................... 17 


\section{ACRONYMS}

CBP Computer-Based Procedures

CCV Correct Component Verification

DOE Department of Energy

HU Human Performance

INL Idaho National Laboratory

INPO Institute of Nuclear Power Operations

LWRS Light-Water Reactor Sustainability

N/A Not Applicable

NASA National Aeronautics and Space Administration

NEO Nuclear Equipment Operator

NPP Nuclear Power Plant

PBP Paper-Based Procedures

R\&D Research and Development

SD Standard Deviation

TLX Task Load Index

U.S. United States 


\section{INTRODUCTION}

The Computer-Based Procedure (CBP) research effort is a part of the Department of Energy (DOE) sponsored Light-Water Reactor Sustainability (LWRS) Program conducted at Idaho National Laboratory (INL). The LWRS program is performed in close collaboration with industry research and development (R\&D) programs that provides the technical foundations for licensing and managing the long-term, safe, and economical operation of current nuclear power plants. One of the primary missions of the LWRS program is to help the U.S. nuclear industry adopt new technologies and engineering solutions that facilitate the continued safe operation of the plants and extension of the current operating licenses.

The nuclear power industry is highly proceduralized, i.e. almost all activities that take place at a nuclear power plant are conducted by following procedures. The paper-based procedures (PBPs) currently used by the industry have a demonstrated history of ensuring the safety of the industry. These procedures are most often paired with human performance $(\mathrm{HU})^{\mathrm{a}}$ methods and tools put in place to anticipate and prevent errors related to hands-on work. The drawback with the current use of paper-based procedures and HU tools is that executing a task becomes time and labor intensive. For example, concurrent and independent verification of procedure steps are often required, which essentially means that at least two people have to be actively involved in the task.

Despite the safety record of the current practice (i.e., combining PBPs and HU tools), there is room for improvement in the use of procedures, notably by taking advantage of technological advancements that increase usability and allow HU tools to be integrated into the procedure. By replacing existing PBPs with CBPs, the industry stands to increase their efficiency and safety. If implemented correctly, a CBP system can reduce the time and effort spent on utilizing separate HU tools. Some HU tools can be completely incorporated into the CBP system in such a manner that the operator does recognize that these tools are being used. Examples of these HU tools pre-job briefs, placekeeping, and peer checks. Other tools can be partly integrated in a fashion that reduces the time and labor required, such as concurrent and independent verification.

The incorporation of advanced technology, such as CBP systems, may help to manage the effects of aging systems, structures, and components. Additionally, the introduction of advanced technology may also make the existing light-water reactor fleet more attractive to the future workforce, which will be of importance when the future workforce chooses between the existing fleet and the newly built nuclear power plants with advanced integrated technology.

The long-term goal for the present research effort is to develop guidance the nuclear industry can use in their discussions with potential CBP system vendors. The guidance will primarily focus on how to best design the graphical user interface of CBPs, as well as how to design the underlying data structure that will be necessary when PBPs are converted to an electronic medium. The path towards the long-term goal is an iterative process where the human factors issues related to CBP usage are systematically addressed and evaluated. The overarching aim of this activity is to collect data that will be used to continuously improve the user interface, which will result in guidance that is based on design principles that have been thoroughly tested and validated. The present research aims to show measureable improvement in the user interface of the $\mathrm{CBP}$ prototype to collect quantitative data on field worker performance while using PBPs versus CBPs.

This research effort is focused on how to improve the efficiency, productivity, and safety of procedure usage by employing CBPs instead of PBPs. In support of this, the research team identified the task flow characteristics, i.e. the aspects of procedure usage that the procedure system must be able to

\footnotetext{
${ }^{\text {a }}$ The Institute of Nuclear Power Operations (INPO) uses the abbreviation HU for human performance. INPO use the abbreviation HP for Health and Physics. The authors of this report decided to follow INPO's standard for abbreviating human performance.
} 
address, regardless of whether it is a paper-based or a computer-based system. Examples of task flow characteristics are:

- Conditional step

- $\quad$ Time dependent step

- Step hierarchy

- Placekeeping

- Correct component verification

- Notes, cautions, and warnings

- Independent verification

The list of task flow characteristics ensures that all aspects of the procedure use are accounted for in this research effort. See Attachment A for the task flow characteristics that have been identified to date. This list will be continuously revised to ensure that it will be as complete as possible.

In addition to addressing all of the task flow characteristics in an efficient manner, CBPs offer the option to move towards a more dynamic presentation of procedures to the user. For example, the CBP system can display only the relevant steps based on operating mode, plant status, and task at hand. This will reduce the risk of the user incorrectly classifying steps as not applicable (referred to as "N/A-ing" steps). The CBP prototype is designed to provide dynamic, context-sensitive instructions to the user.

This report describes the development and evaluation of the most current version of the CBP prototype. The redesign of the CBP prototype was based on results and insights gained from previously conducted research activities. These activities are briefly described in section 1.1. The evaluation study, including a description of the design decisions made while revising the CBP prototype, is described in section 2. A general discussion and conclusions are to be found in section 3.

\subsection{Background - Previous Research Activities}

Figure 1 describes the activities conducted in the research effort thus far. These activities are documented in two reports. The research effort started out with activities aimed to characterize the current usage of procedures in the nuclear industry. These activities are discussed in detail in ComputerBased Procedures for Field Workers in Nuclear Power Plants: Development of a Model of Procedure Usage and Identification of Requirements (Oxstrand \& Le Blanc, 2012). The first evaluation study (Study 1) is documented in Evaluation of Computer-Based Procedure System Prototype (Oxstrand, Le Blanc, \& Hays, 2012). Each of these studies is summarized below to provide the necessary background information for the present evaluation study (Study 2). 

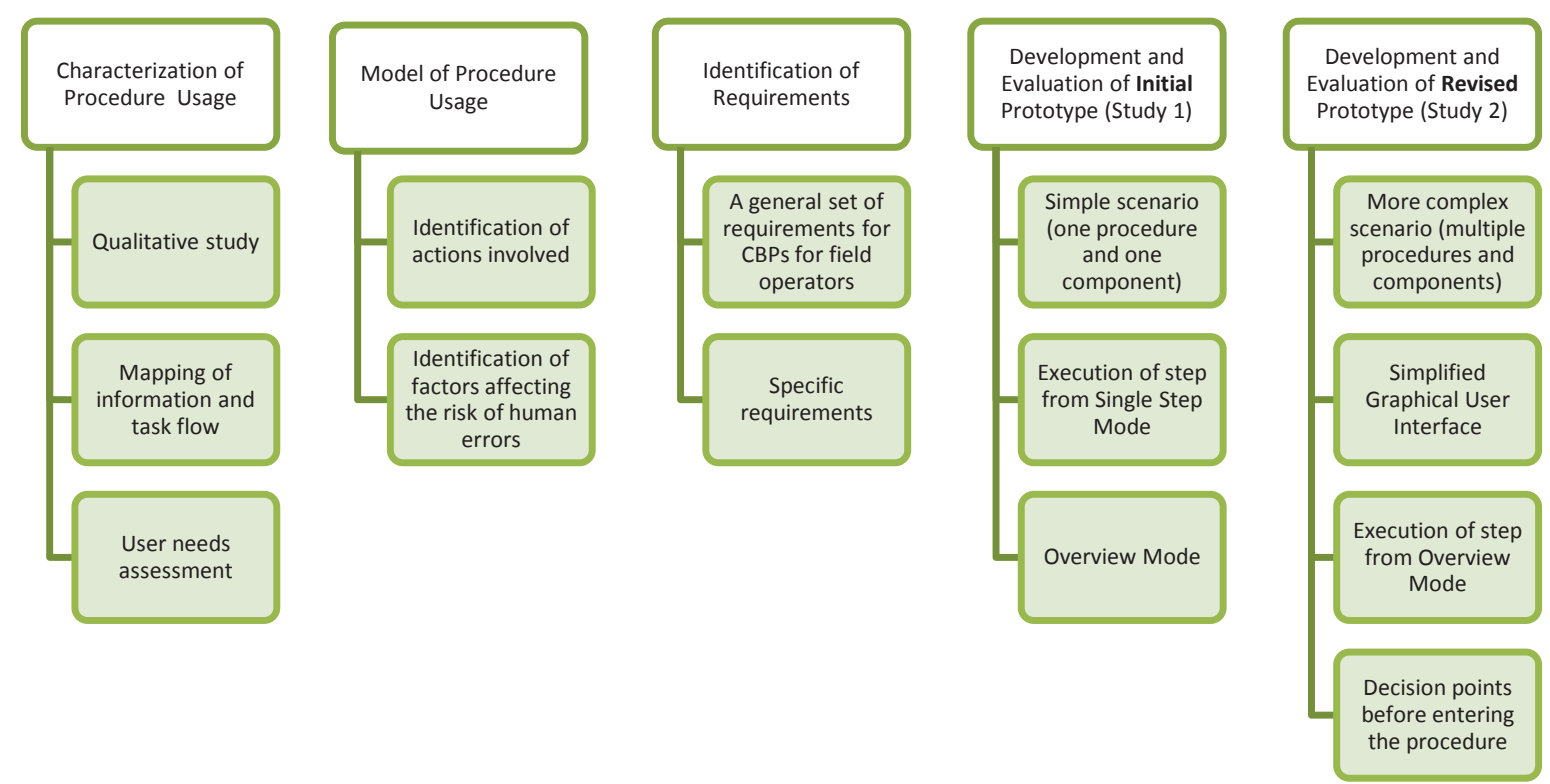

Figure 1 - Research Activities Conducted To Date

\subsubsection{Characterization of Procedure Usage}

In order to understand how to improve the use of procedures in the nuclear industry it is important to study current work practices. The research team conducted a qualitative study, mapping activities of both information and task flow, and a user needs assessment to gain the understanding needed to move forward in the process of increasing safety and efficiency at nuclear utilities by replacing PBPs with CBPs.

The qualitative study was conducted at a nuclear power plant and involved participants from four nuclear power utilities and five research institutes. The study consisted on-the-job observations of field operators, interviews, and focus group discussions. The primary goal of the qualitative study was to develop a model of procedure use that would characterize how operators execute procedures under the current process.

The insights gained from the qualitative study included both the need for requirements and standards for CBPs and the need to design CBPs in a manner that will to enhance human performance compared to PBPs (not simply replace the existing process with an identical electronic process). In addition to the qualitative study, a utility survey was conducted to gather input on the nuclear utilities' current plans for implementing CBPs, the current infrastructure in place to support CBPs, as well as the perceived or real barriers to implement CBPs systems. The most significant finding from this user needs assessment activity was that there is substantial utility interest in implementing CBPs. All of the participating utilities reported that CBPs for field operators were part of their long-term vision. Sixty-six percent reported that CBPs for control room operators were in the long-term vision (Le Blanc \& Oxstrand, 2012).

\subsubsection{Model Development and Identification of Requirements for CBPs}

The research team used the results from the qualitative study to develop a model of procedure usage. The model is design to emphasize the different physical and cognitive activities that are needed to perform a single procedure step. The model also identifies factors affecting the risk of human errors while conducting the procedure step. The model contains a detailed task flow of the execution of a single procedure step, techniques used to make decisions while executing the procedure step, conditions that must be satisfied to ensure task success, and cognitive factors that influence the likelihood of error. 
During the model development process, the research team created a set of minimum requirements needed to address the specific challenges with field procedures. For example, the requirements state that the CBP should:

- Guide operators through the logical sequence of the procedure

- Ease the burden of placekeeping for the operator

- Make the action steps distinguishable from information gathering steps

- Alert operator to dependencies between steps

- Ease the burden of correct component verification for the operator

A more detailed description of the model development and identification of CBP requirements can be found in Oxstrand \& Le Blanc (2012).

\subsubsection{Study 1: Development and Evaluation of a CBP Prototype}

The model of procedure usage highlighted parts of the procedure execution process that can be improved by the support of a CBP system. The model and the identified requirements were utilized to identify which features or functionalities should be built in to the CBP to address the portions of the procedure execution process where the current PBPs do not provide optimal support. The researchers used two criteria for the selection of features to implement. These criteria are 1) what is needed to support successful execution of the procedure step, and 2) is the feature essential to show potential benefits to using CBP instead of PBP. The research team concluded that the focus for the initial prototype should be on context sensitivity, simplified step logic, automatic placekeeping, and automated correct component verification.

Field workers have to carry procedures with them as they move around in the field. For the CBP prototype to be usable in this context, it must be easily portable. Therefore, the CBP prototype must be accessible from a handheld device. The qualitative study identified that different field organizations, (e.g. field operators and maintenance technicians) might have different preferences regarding screen size. The research team decided to use a small handheld device even though the screen real estate was limited because it could be easily slipped into a pocket (which was listed as an essential requirement for field operators who often need hands free to climb ladders and crawl though small spaces). Additionally, it was concluded that using a small screen would be most challenging in terms of developing a well designed CBP user interface. If a successful user interface could be developed using the constrained screen size of a small device, it should be easier to adjust the initial design to fit a larger device than it would be to go the other way around.

The research team evaluated the initial CBP prototype in Study 1, which was conducted at a nuclear power plant. Study 1 compared operator performance while conducting a task with a CBP to operator performance while conducting the same task using a PBP. The research team used both objective measures and subjective workload assessments to compare the performance. Study 1 also obtained feedback regarding the usability of the CBP interface.

Thirteen technicians from different disciplines at the nuclear power plant participated in the study. The average age of participants was 48 years. Most of them used paper procedures as a part of their daily job duties. Participants conducted the same scenario twice, once with the PBP and once with the CBP. The order of procedure used was counterbalanced across participants.

Results from the study showed that all participants were able to successfully execute the task with the CBP prototype, despite the fact that participants received minimal training on the prototype before conducting the task. This indicates that the CBP interface is easily learned and relatively intuitive to use. However, participants did provide suggestions for how to improve the CBP interface. For example: 
- The CBP should indicate when there is additional text that the user needs to scroll down to read.

- The user should be able to execute the procedure from the overview mode.

- The user should have the ability to "pause" the procedure to indicate that he is no longer actively working on it.

The research team used the findings of Study 1 to guide revisions of the prototype, which was evaluated in Study 2. The user interface was improved to address more of the identified task flow characteristics. The next section will describe Study 2 in greater detail, including the revisions made to the CBP prototype.

\section{STUDY 2: EVALUATION OF REVISED CBP PROTOTYPE}

The purpose of the second study was to evaluate whether the modification improved usability of the prototype. Additionally, this study was designed to provide quantitative performance data that could be used to compare CBP and PBP usage.

\subsection{Method}

\subsubsection{Participants}

Ten employees at an operating nuclear power plant (NPP) participated in this study. Nine were Nuclear Equipment Operators (NEO) and one was a training manager. The mean age of the participants was 40 years $(S D=11$ years). The participants had an average of 10 years of experience $(S D=8$ years $)$ in their current role. All participants were male.

\subsubsection{Materials}

This section describes the selection process for the procedure and scenario, as well as the three different types of surveys that were used in the evaluation study. The redesign of the CBP prototype is also described in detail, including the rationale for the design decisions.

\subsubsection{Procedure Selection}

Results from the previous study indicated that it may be difficult to detect performance advantages with CBPs if the procedure and scenario are too simple. Therefore, the researchers worked with plant personnel to select a more complex procedure and scenario for this evaluation study. The procedure utilized was an existing procedure used to train field operators in a functioning flow loop training facility; the specific scenario involved initiating the cold water system and the control loop system. The features that contributed to the increased complexity in the scenario chosen for this study include the presence of multiple conditional statements and branching to other procedures. These features of the procedure and scenario allowed the research team to better assess the impact of context sensitivity in the CBP prototype.

\subsubsection{Computer-Based Procedure Prototype}

The CBP prototype was implemented using an Apple iPod, using the same software platform as described in Oxstrand et al. (2012). The research team modified the user interface based on feedback from Study 1 (Oxstrand et al., 2012). The most significant modifications to the prototype will be discussed in this section. In short, the modifications are:

- Revision to the software code to produce faster response time and fewer delays

- Elimination of the "Start Step" button

- Elimination of Single step mode

- Ability to execute procedure from overview mode 
- Indication of what decisions led an operator down a particular procedural path

An important modification of the revised CBP prototype, which is not reflected in the graphical user interface, but has a great impact on the user experience, is the improvement of system response time. Participants in the initial study did not use the overview mode as much as the researchers expected. This was attributed to the time it took to switch between the single step mode and the overview mode. It also took a noticeable amount of time for the next step to load in the initial prototype. The revised prototype performed much quicker, such that loading times were not noticeable.

The researchers designed the interaction with the initial CBP prototype to be analogous to the current PBP placekeeping method (i.e., circle/slash). In the initial prototype, users indicated they were starting a step by pressing a "Start step" button, (similar to circling the currently active step in a PBP). One of the findings from the first evaluation study was that the participants felt that the "Start Step" button was unnecessary, and led to too much clicking. Figure 2 shows how the active procedure step is presented in both the initial and the revised prototypes (though it should be pointed out that the issue of whether the "start step" button was necessary was controversial among the collaboration partners at the plant). It was concluded that some indication of when a step was started is necessary in a few situations, but that default behavior of an electronic procedure system should be to automatically activate the next step in the sequence once the previous step was marked complete. The revised CBP prototype used in Study 2 automatically marked the next step as active once the previous step was marked complete. To further reduce the need for user input, the system automatically navigated to the active step.
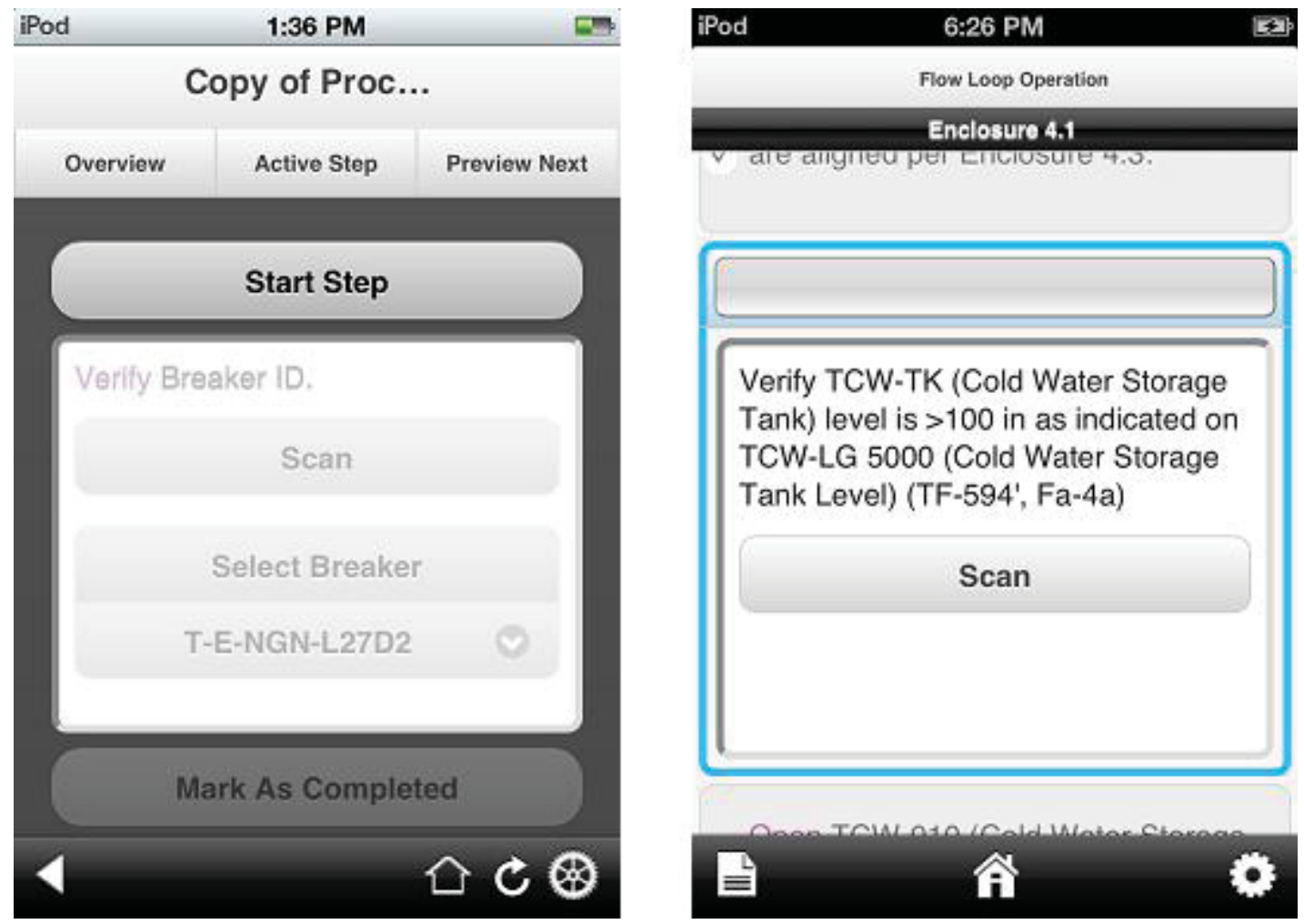

Figure 2 - The Presentation Of The Active Step In The Two CBP Prototypes

The initial prototype had two main viewing modes: the overview mode and the single step mode. The overview mode allowed the user to review the full procedure before starting the task as well as the ability to look back or ahead while executing the task. The intent of the overview mode was to allow the operator to easily see which steps have been executed and which has not. The single step mode displays one 
procedure step at the time. The operator uses the single step mode to execute the step. The operator can either use the single step mode to look ahead step by step or navigate to the overview mode find out more information regarding conducted or remaining steps in the procedure.

Figure 3 depicts the overview mode of the initial CBP prototype (Study 1) and the revised CBP prototype (Study 2). In both versions, a blue border indicates the active step. With the elimination of the single step view in the revised prototype, it is important that the operator can easily identify the active step while looking ahead or reviewing past steps. In order to make the active step more visible, the active step is filled with a blue gradient in the revised version.

One of the rationales for the single step mode was to make the best of the available screen real estate. More importantly, the single step was thought to help the performer focus on the active step. However, results from Study 1 indicated that even though the step was readable and did help the operator focus on the active step, it could also reduce awareness of the overall picture. Figure 2 shows how the two versions of the active step are presented to the operator as he/she is about to start the step. Figure 3 portrays how the active step is presented in the overview. When the operator clicks on the step, it expands and enables additional functionality not displayed when collapsed, such as the scan function. Figure 2 shows the expanded version of an active step.

As shown in Figure 3, the step hierarchy is also handled differently in the two versions. The initial version kept the original step numbering scheme used in the paper-based version of the same procedure; in the revised version, there are no numbers. The rationale for removing the numbering system is that the step numbers may cause confusion when the prototype merges different enclosures or sections within the procedure in order to present seamlessly the sections needed to perform the specific task. Instead of using a step numbering scheme, the redesigned interface indicates step hierarchy by indenting substeps and bolding the active parent step. Additionally, the black title bar shows the section or parent to the active substep. These modifications maintain the important contextual information (i.e., what task is being completed) while eliminating the numbering scheme, which may become confusing when steps are omitted because they are not relevant to the current conditions. 

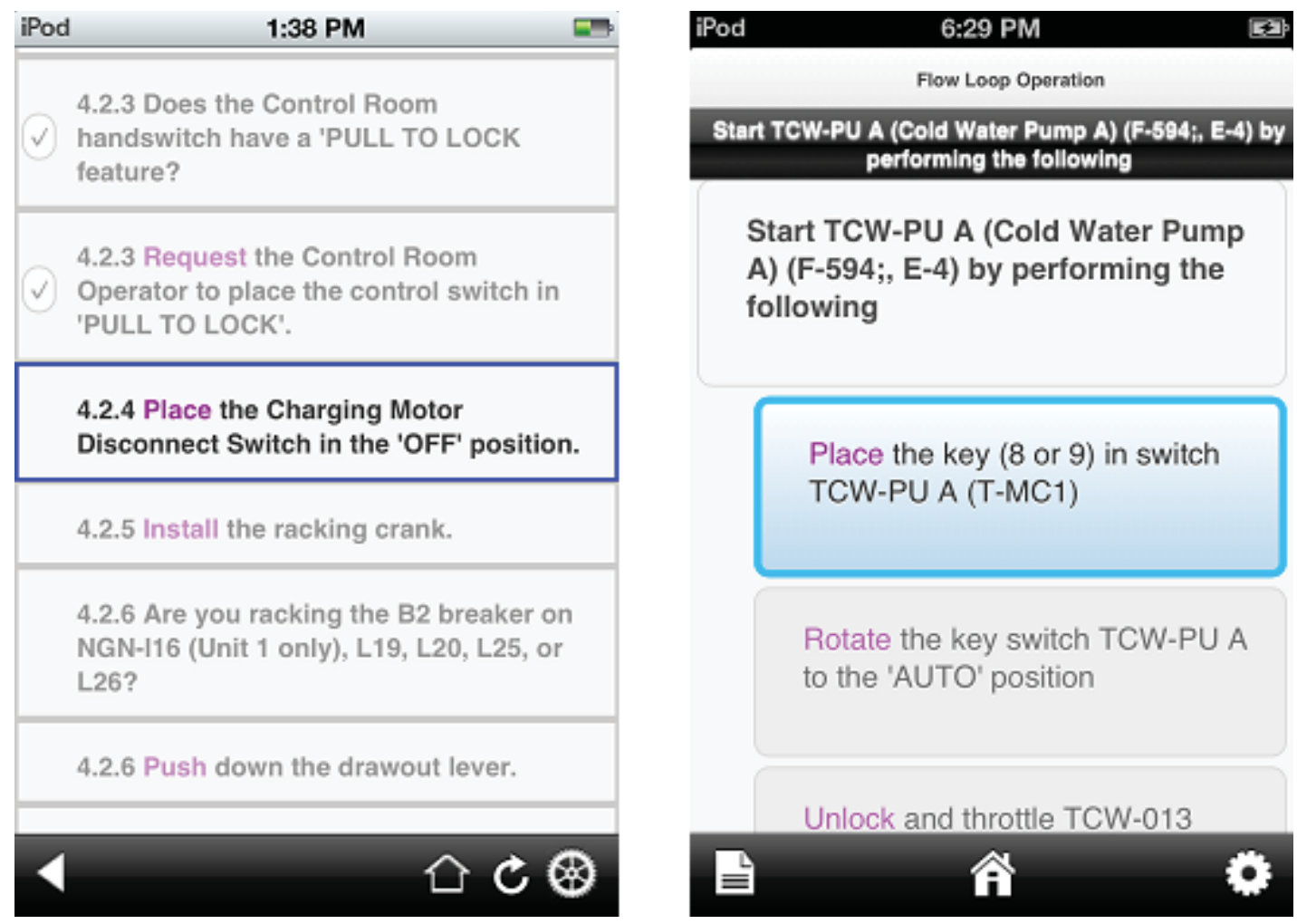

Figure 3 - The Overview In The Initial And The Revised CBP Prototype

Another noticeable change made to the revised version of the overview is the increased font size. One of the primary reasons for including the single step mode in the initial prototype was to make the best of the small screen real estate. Due to the removal of the single step mode in the revised version of the CBP prototype, it is important to increase the readability in the overview mode, the mode with which the operator will execute the procedure.

In the redesigned CBP prototype used in Study 2, the steps marked not applicable are grayed out. Figure 4 displays how steps that are applicable and not applicable are presented in the revised interface. Steps that eventually will be performed when executing the procedure are light gray, and the not applicable steps are dark gray. The operator can click on the information icon to view a pop-up box that presents the decision that lead to the disabling of the step. 

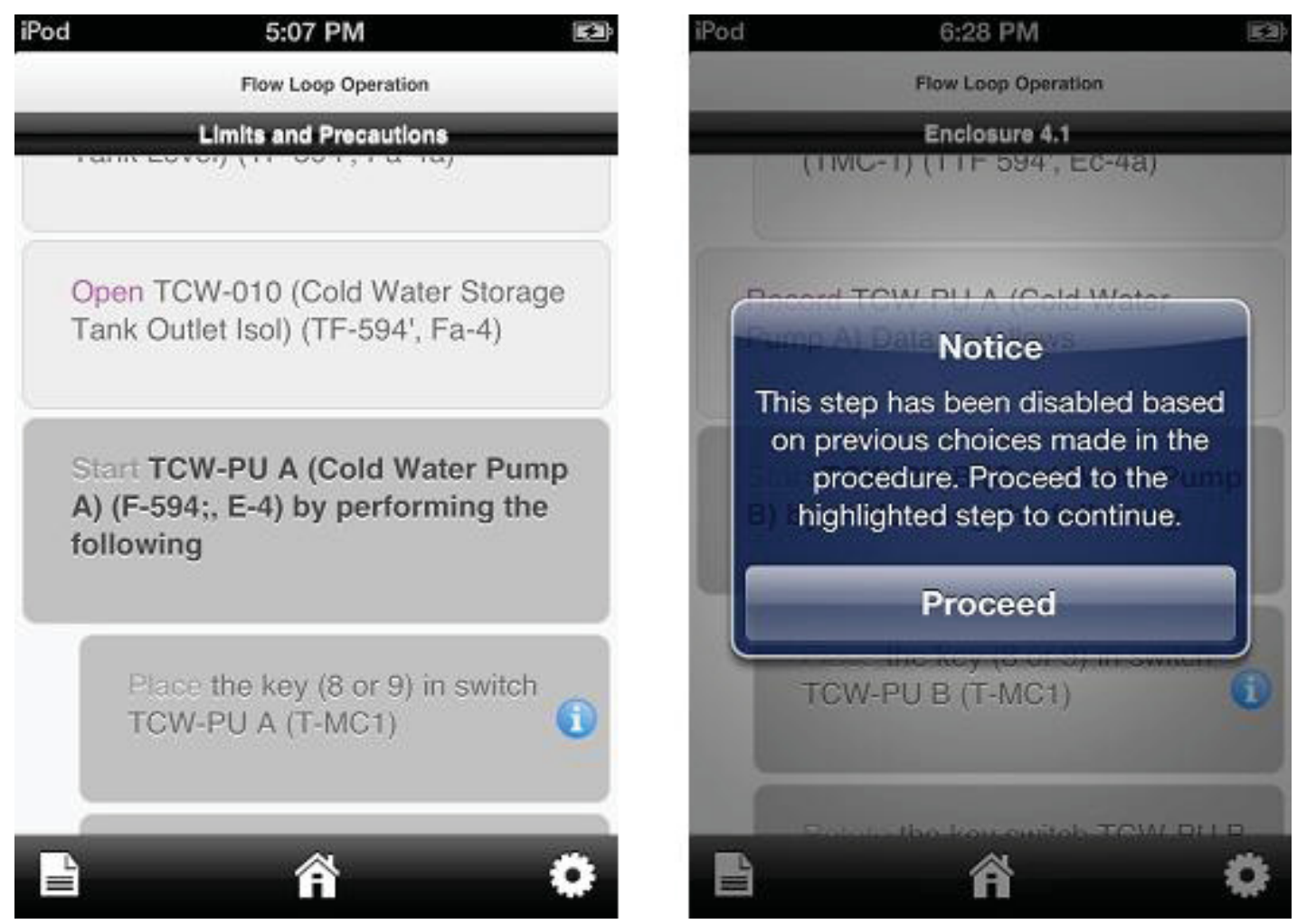

Figure 4 - The Difference Between Step To Be Performed And Not Applicable Steps

The manner in which notes, cautions, and warnings were presented in the initial CBP prototype has been improved in the redesigned version. Instead of presenting the notes, cautions, and warnings as a procedure step that has to be started and marked as completed, the revised CBP closely mirrors how these are presented currently in PBPs; see Figure 5. In PBPs, the notes, cautions, and warnings are inserted before the step(s) to which they apply. They are not a procedure step per say, but the operator is required to read and acknowledge them. As done when using PBPs, the operator has to acknowledge in the CBP that the caution was read by clicking "Next." The operator cannot proceed until the caution is acknowledged. A yellow triangular icon indicates if the subsequent procedure step is affected by the note, caution, or warning. To find out which note, caution, or warning applies, the operator can click on the icon, and a pop-up will provide this information. 


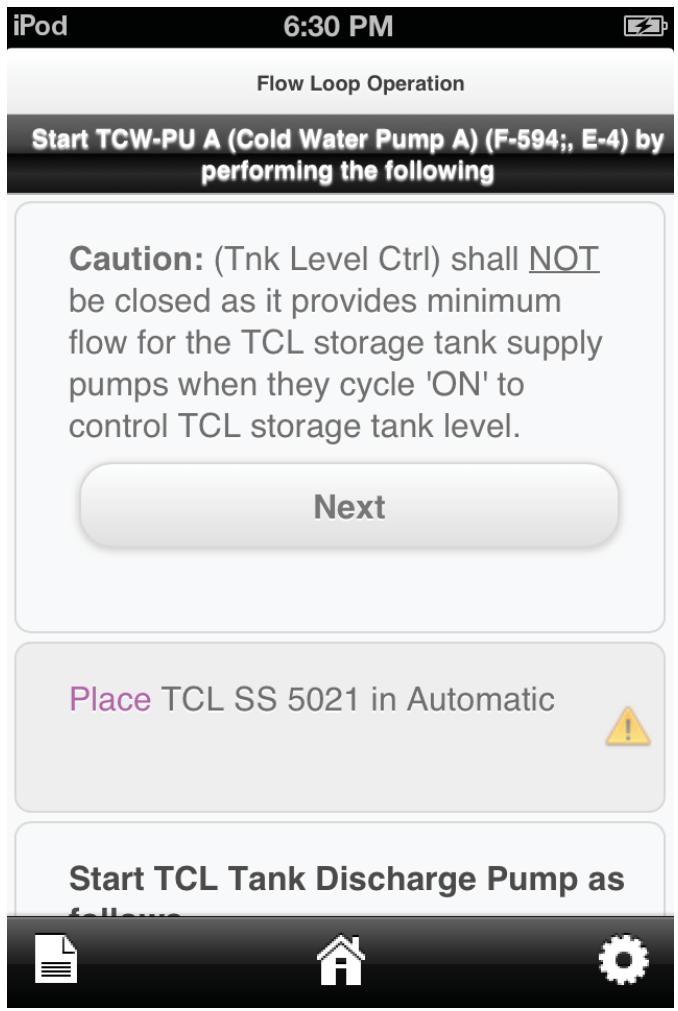

Figure 5 - The Presentation Of A Caution In The Revised CBP Interface

One of the primary benefits of CBPs compared to traditional PBPs is the dynamic aspect of using electronic technology. Compared to static text on a sheet of paper, the information presented in the computerized procedure could potentially be updated based on mode of operation, plant status, the task to be performed, and user input while executing the task. The goal of a context-sensitive procedure is to minimize the risk of incorrectly marking procedure steps as not applicable. A well-designed CBP system will lead the operator down the path of relevant steps without burdening the operator with the task of N/A-ing steps. The level of context sensitivity that can be built into a CBP system depends on multiple issues, such as availability of plant information and wireless networks. Both the initial and revised CBP prototypes are designed to make decisions based on context provided by the user, e.g. the answer to questions regarding conditional statements in the procedure, selection of tasks to be performed, etc. This an important point, because it shows that the availability of a wireless network is not necessary to provide the operator with dynamic context-sensitive information.

The procedure used in the initial evaluation study was quite simple (i.e., it did not consist of many context-dependent variables, such as decision points or branching points). However, the scenario was complex enough to enable an initial evaluation of context sensitivity. Figure 6 depicts two ways context sensitivity was implemented in the initial prototype used in Study 1. The CBP prototype enabled the relevant steps depending on what type of activity the operator was tasked to execute, in this case "Disconnect Breaker." The steps relevant to the three other options were N/A'd by the system.

Another feature of the CBP prototype is the simplification of step logic. Many operators indicated that conditional statements can be cognitively demanding to process. Where conditional statements were used in the traditional PBPs, such as If/Then instructions, simplified step logic was implemented in the initial CBP prototype. The If/Then statement was reworded to a Yes/No question. Based on the answer, the operator would be lead down the path of relevant steps. 

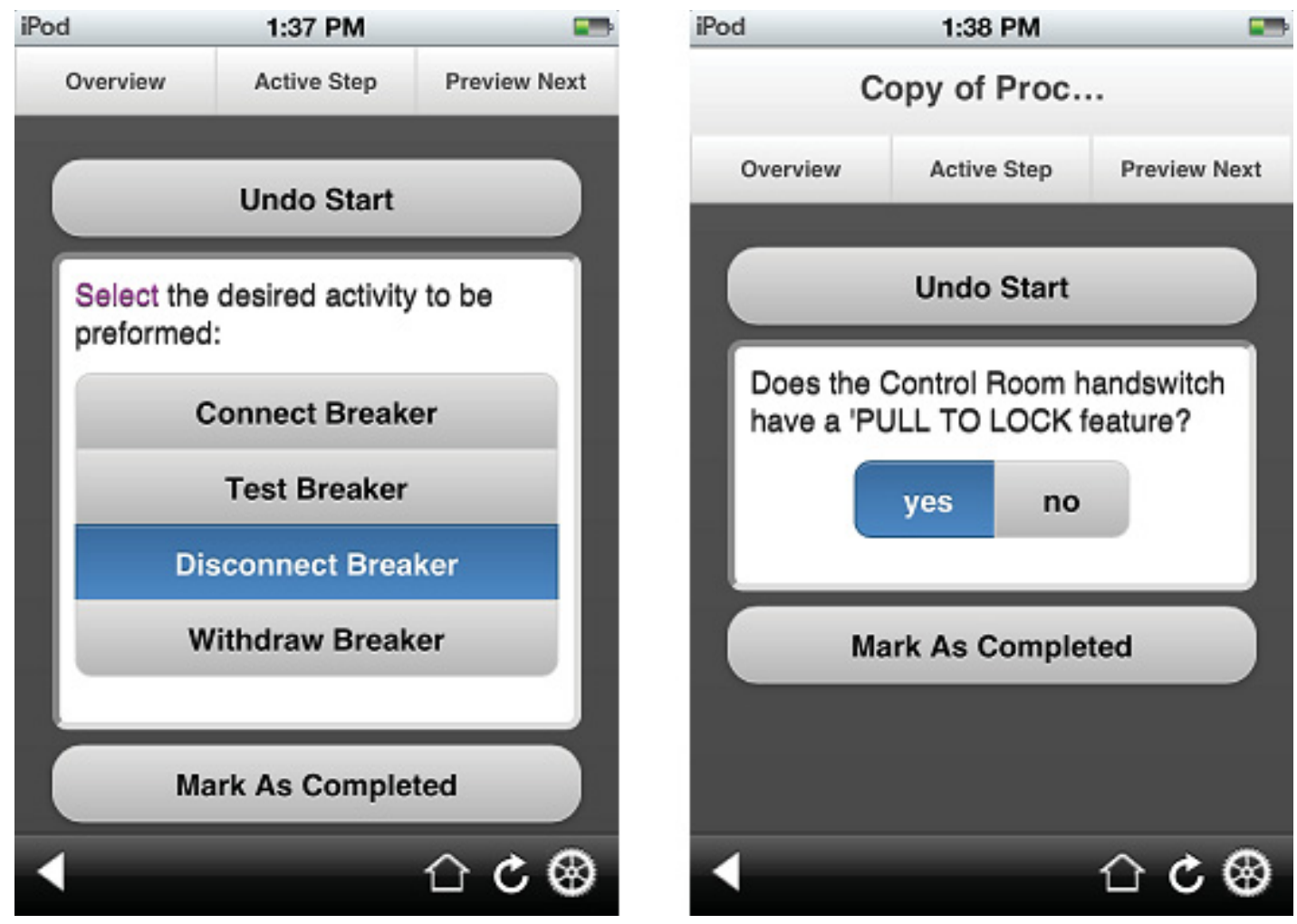

Figure 6 - Context Sensitivity In The Initial CBP Prototype

Results from Study 1 also showed that, based on what is communicated in the pre-job brief, the operator has most of the information necessary to determine the appropriate path through the procedure. Therefore, when designing the revised CBP prototype, the research team determined that it would improve usability of the CBP to provide this pre-job brief input to the CBP system once, rather than requiring the operator to repeatedly do so throughout the execution of the procedure. Decisions about which enclosures or sections of the procedure will be executed and what component or equipment will be the focus of the task can usually be made before starting the procedure. Currently, the supervisor and the operator will go through the paper-based version of the procedure and N/A the steps that they know will not be a part of the execution. By letting the CBP system conduct the N/A-ing based on pre-job brief input, the operator and the supervisor will save time that they can use to conduct other tasks.

The scenario used for the second evaluation study, described in detail in other sections of the report, was designed in such a way that the pre-job brief informed the operator which enclosures to perform and what pump to operate. By making these decisions up front, the irrelevant steps were marked not applicable before the operator started the procedure (see Figure 7). Conditional steps that could not be resolved up front were handled the same way as in the initial CBP prototype. 


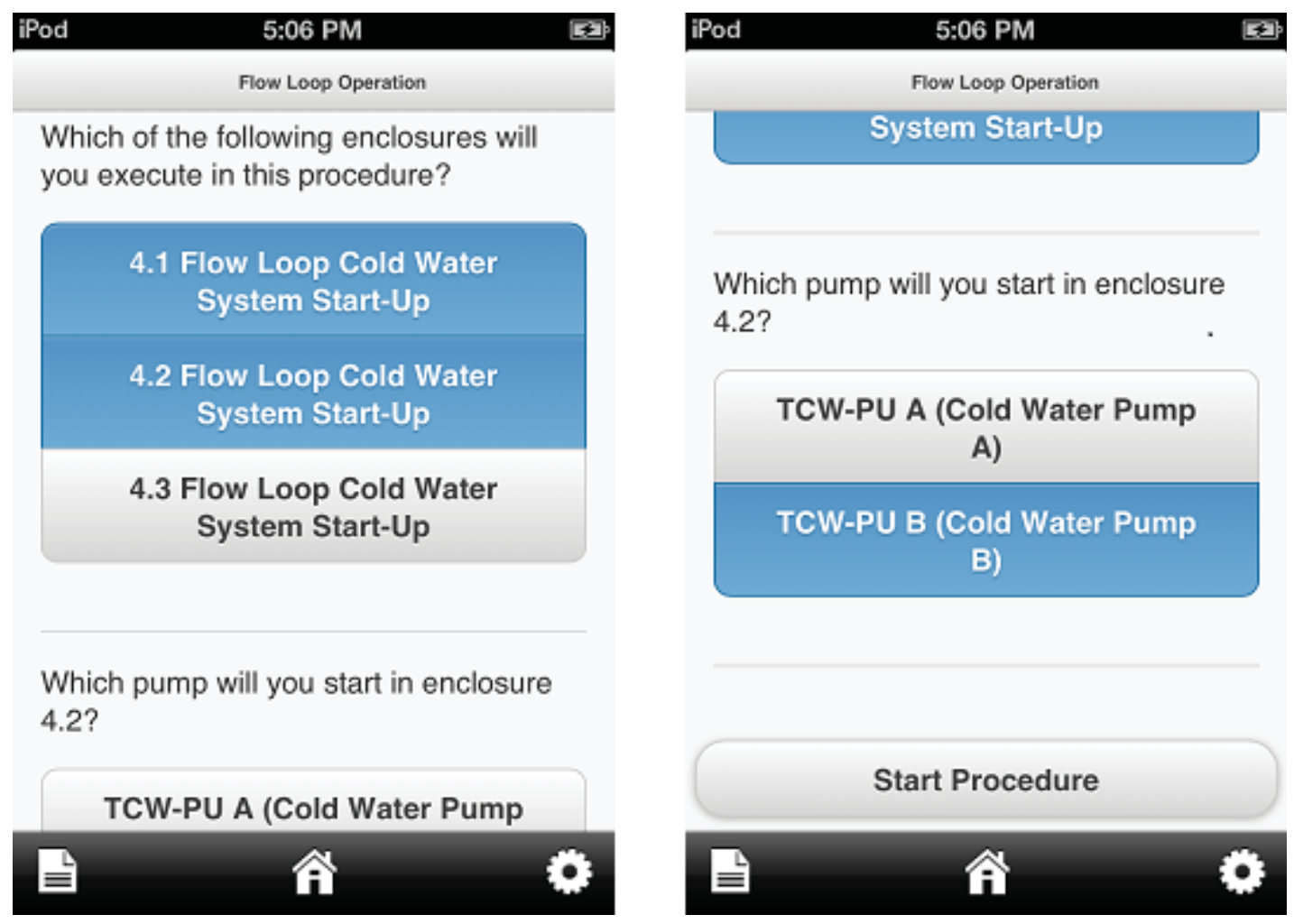

Figure 7 - Decision Made Based On Information Shared In The Pre-Job Brief

One insight learned from the qualitative study is that correct action on an incorrect component or equipment can have negative consequences related to the safety of the plant. The occurrence of this type of human error is rare. However, the potential severity of the consequence justifies work to further reduce the occurrence of these errors. Most procedure steps where an action is performed on a piece of equipment require the performer to verify that the correct component is to be operated. This is commonly called correct component verification $(\mathrm{CCV})$.

The opportunity to conduct CCV using the CBP system was implemented in the initial CBP prototype. By utilizing the integrated camera in the handheld device, the performer scanned the barcode associated with the component. The CBP system verifies that the correct barcode was scanned. However, due to the limitations of the scenario used in the initial evaluation study, this functionality was not thoroughly evaluated. Based on the initial feedback gathered, the CCV functionality was redesigned and reevaluated. The redesigned flow is as follows: the performer starts the active procedure step by clicking on "Scan", as shown above in Figure 2, and then proceeds to scan the component's barcode. If the correct barcode is verified by the system, the performer can continue to execute the step. If a barcode associated with another component is scanned by mistake, the system will prompt the performer via a pop-up box. The system will bring the performer back to the option to scan the barcode, see Figure 8 . The performer cannot proceed to execute the step until the correct component is verified. 

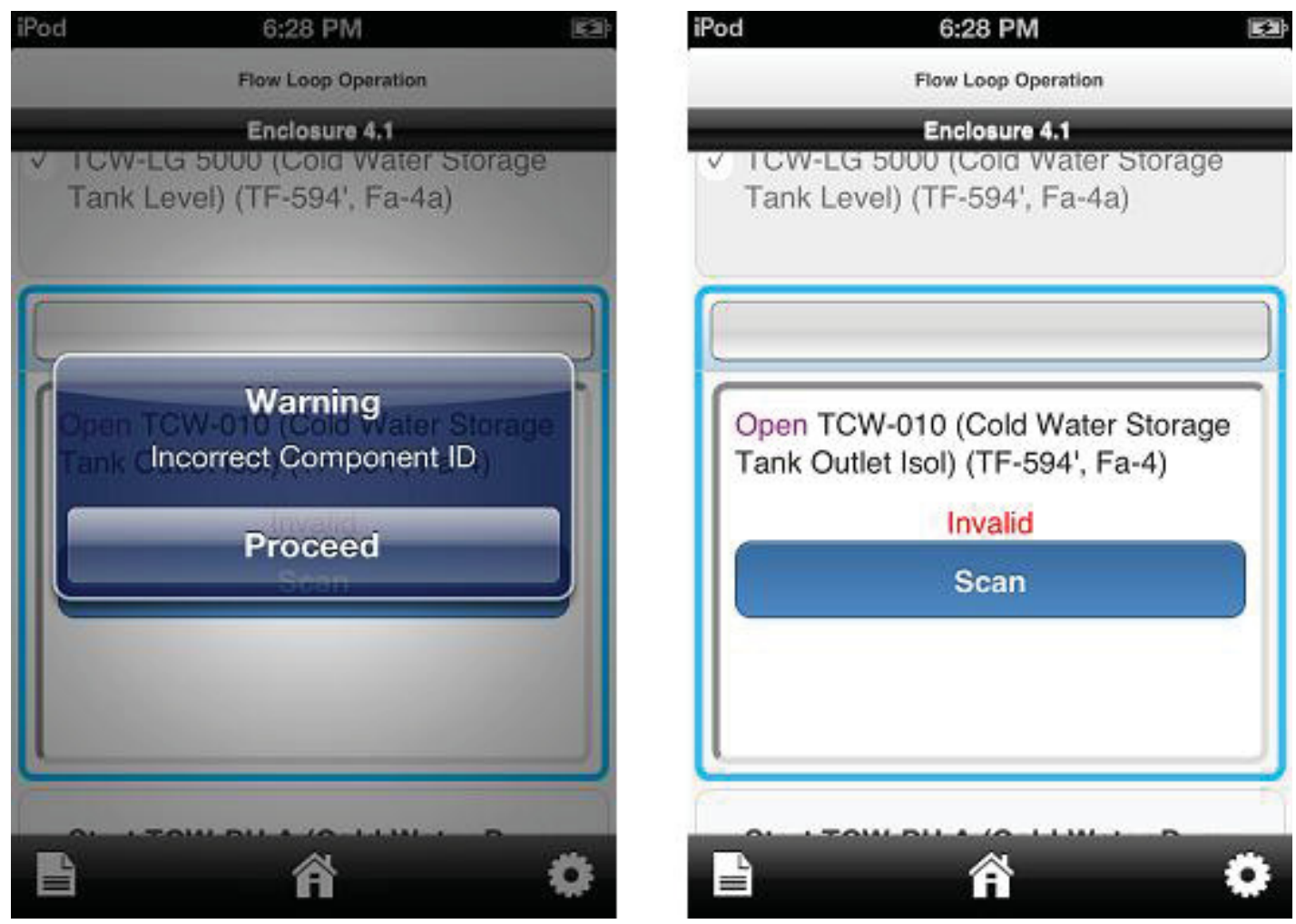

Figure 8 - System Response When Incorrect Component Is Scanned

A task flow characteristic that was added to the redesigned CBP prototype is what is commonly called bulleted steps. These are steps within a step that may be performed in any order and all must be executed before proceeding to the next step. In current PBPs, these steps are presented as bullet lists. Figure 9 shows an example of how bulleted steps are presented in the redesigned CBP prototype. In this specific case, the performer is asked to record data points related to a cold water pump. The performer provides the data input by clicking on the associated text box and uses the keyboard to manually insert the data point. 

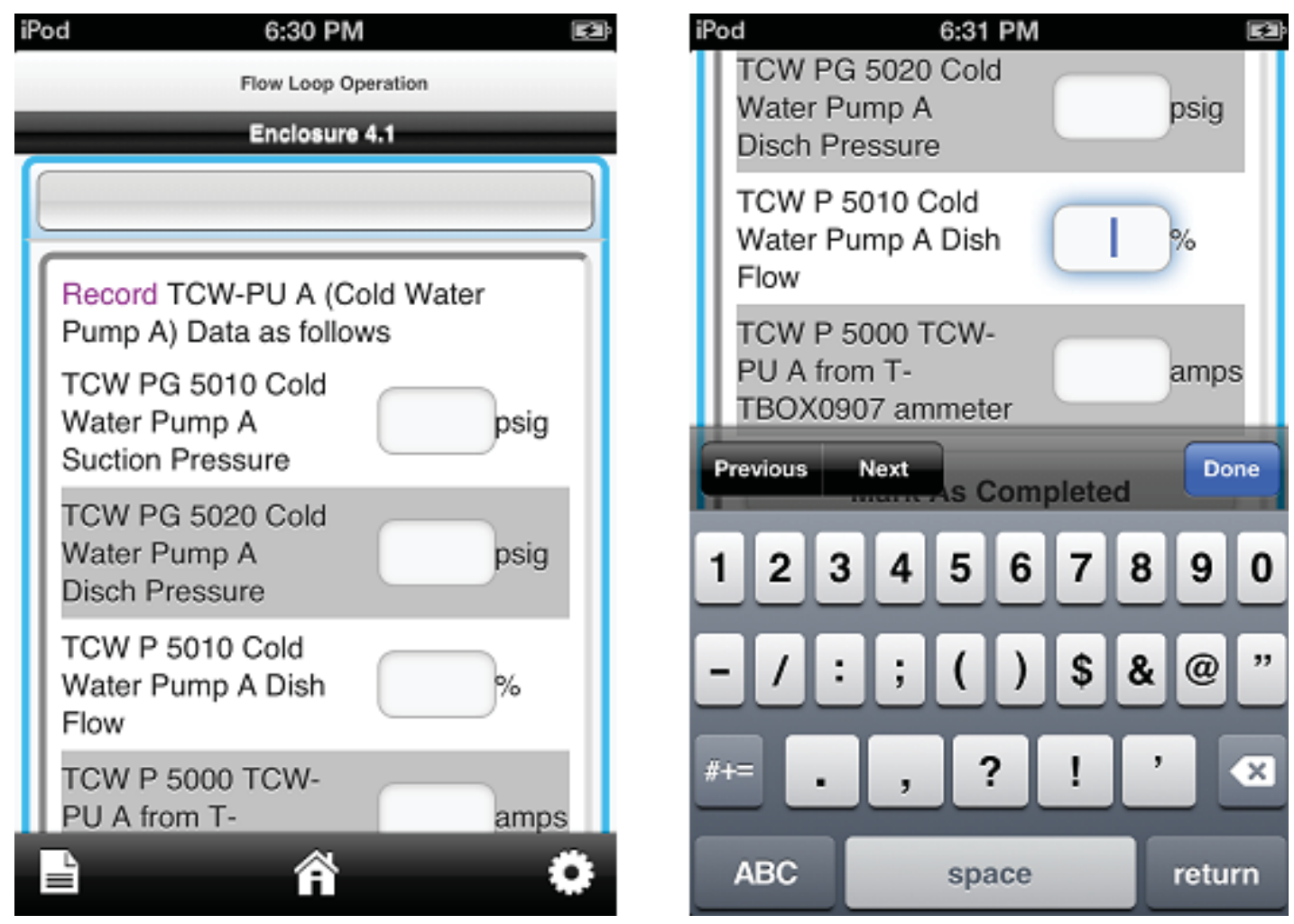

Figure 9 - Example Of Substeps That Can Be Executed Out Of Sequence And How To Record Data

\subsubsection{Surveys}

A brief demographics survey was developed so that researchers could explore the effects of age and experience on the use of CBPs. This survey is presented in Appendix B.

Computer-based procedures are intended to reduce operator workload, and help the operator to focus on the task instead of on using HU tools; however, managing the interface of a new computerized system can actually increase workload rather than decrease it (O'Hara, 2002). The researchers developed the $\mathrm{CBP}$ prototype based on rationale provided from previous research in order to maximize the degree to which the CBP supports procedure execution However, it is important to evaluate workload in each iteration of the prototype development so the CBP prototype can be constantly improved, resulting in a final prototype that supports performance without adding additional workload. To assess the workload associated with using the CBP prototype compared with the traditional PBPs, researchers used the NASA Task Load Index (TLX) assessment tool (Hart \& Staveland, 1988). The NASA TLX was administered using paper and pencil and is included in Appendix C.

Researchers developed their own usability survey to assess the interface of the CBP prototype. The 8 -item survey targeted the availability of information, ease of navigation, and ease of use of the CBP interface. Researchers also developed a 6-item usability survey to assess the usability of the handheld device (in this case, the iPod).

Researchers also developed a debrief questionnaire to gain more detailed feedback on the design of the user interface and the overall experience using the CBP. The questions on this survey were openended. The 8-item usability survey, the 6-item usability survey, and the debrief questionnaire are included in Appendix D and E. 


\subsubsection{Design}

This evaluation study was designed to determine whether the CBP prototype offers performance advantages over the PBP. Therefore, the main factor in this study was the procedure presentation style (PBP or CBP) and it was manipulated within participants.

The main dependent variables in this study were completion time and deviations in the optimal procedure path. In order to investigate the CBP effect on performance time, researchers measured the completion time of each scenario via a stop watch. The timer was started when the participant indicated that they were entering the first section of the procedure, and stopped when the participant completed the final step in the procedure.

The researchers also recorded the number of deviations from the optimal procedure path. Researchers worked with plant personnel to identify possible deviations prior to conducting the study. Deviations were broken down into three categories: recovered deviations, non-recovered deviations and placekeeping errors. Recovered deviations were defined as situations in which operators were not following the optimal path, but ultimately recovered. For example, when an operator walked to the wrong location or scanned the wrong component (but ultimately found the right component or location), it was recorded as a recovered deviation. Non-recovered deviations were defined as deviations in which the operators failed to take an action specified in the procedure or took the wrong action. Placekeeping deviations were defined as temporarily skipping a step (an omitted step was classified as a non-recovered error) or not marking a step as complete. The researchers chose to classify the deviations separately because they wanted to capture all deviations; however, the non-recovered deviations would have a greater impact on system performance and safety than the recovered ones.

\subsubsection{Experimental Protocol}

Participation in the evaluation study was conducted in two sessions. During the first session, the participants were familiarized with the task and trained on how to use the CBP prototype. During the second session, participants executed the scenario with the CBP and with the PBP. Upon arrival at the first session, participants signed an informed consent form. Participants were then randomly assigned to complete the scenario with the CBP first or with the PBP first (order was counterbalanced). Participants then filled out a brief demographics survey. Following the completion of the demographics survey, participants were instructed on how to use the CBP. The researchers trained the participants to navigate through the CBP, and then completed a simulated walk-through of the procedure to demonstrate how to use features such as barcode scanning. The training took approximately 30 minutes.

The participants returned the following day to execute the procedure using both the PBP and the CBP. Participants were given a pre-job brief which included a discussion of the task to be completed, the potential hazards, and other important safety concerns. If the participant was assigned to the PBP-first condition, then he completed the procedure with the PBP. When the participant indicated that he was starting the first section of the procedure (i.e., reviewing the prerequisites), the researcher started the stopwatch. The researcher watched the scenario closely and recorded any deviations. The researchers also took detailed notes as the operators executed the scenario in case additional insights could be gleaned that were not gathered via other methods. Once the final step was completed, the researchers stopped the stopwatch and recorded the time. The participant then filled out the NASA-TLX for the PBP condition. The participant then completed the same scenario using the CBP in the same manner. Following the execution of the scenario with the CBP, the participant completed the NASA-TLX for the CBP task, the CBP usability survey, and the debrief survey. If the participant was assigned to execute the task with the CBP first, the experiment proceeded in the same manner except they executed the scenario with the CBP before the PBP.

The researcher had to make one potentially important modification to the above protocol because equipment in the flow loop facility was malfunctioning. When the first participant executed a portion of 
the scenario, it was discovered that an air operated valve was malfunctioning. Maintenance personnel were not able to repair the valve during the visit, so the researchers instructed the participants to simulate the portion of the procedure that relied on that valve. For that portion of the procedure, the participants ran through the procedure as though they were conducting it, but did not actually manipulate the equipment as they did for the remainder of the procedure. The portion of the procedure that was simulated is marked in appendix F. This modification was the same for both eth CBP and PBP conditions.

\subsection{Results}

Preliminary analysis of the data included the order (CBP-first or PBP-first) as a factor. However, there were no significant effects or interactions with order. In other words, the order that operators executed the scenarios (either CBP-first or PBP-first) did not have a detectable effect on any of the factors analyzed in the results. Therefore order is excluded in the analysis and discussion for the sake of simplicity.

\subsubsection{Objective Performance}

Performance using the CBPs was assessed by comparing completion times and number of deviations from the optimal procedure path to performance using PBPs.

\subsubsection{Scenario completion time}

The time to complete the scenario was measured in seconds using a stopwatch. A 2 X 2 (order by presentation style) mixed analysis of variance indicated that there was a significant main effect of presentation style (CBP or PBP) on the scenario completion time $\mathrm{F}(1,7)=7.12, \mathrm{p}=.032$. It took longer to complete the scenario with the CBP $(M=1724$ seconds, $\mathrm{SD}=358)$ than the PBP $(\mathrm{M}=1231$ seconds, $\mathrm{SD}$ $=274$ ). There was no significant main effect of order and there were no significant interactions with order.

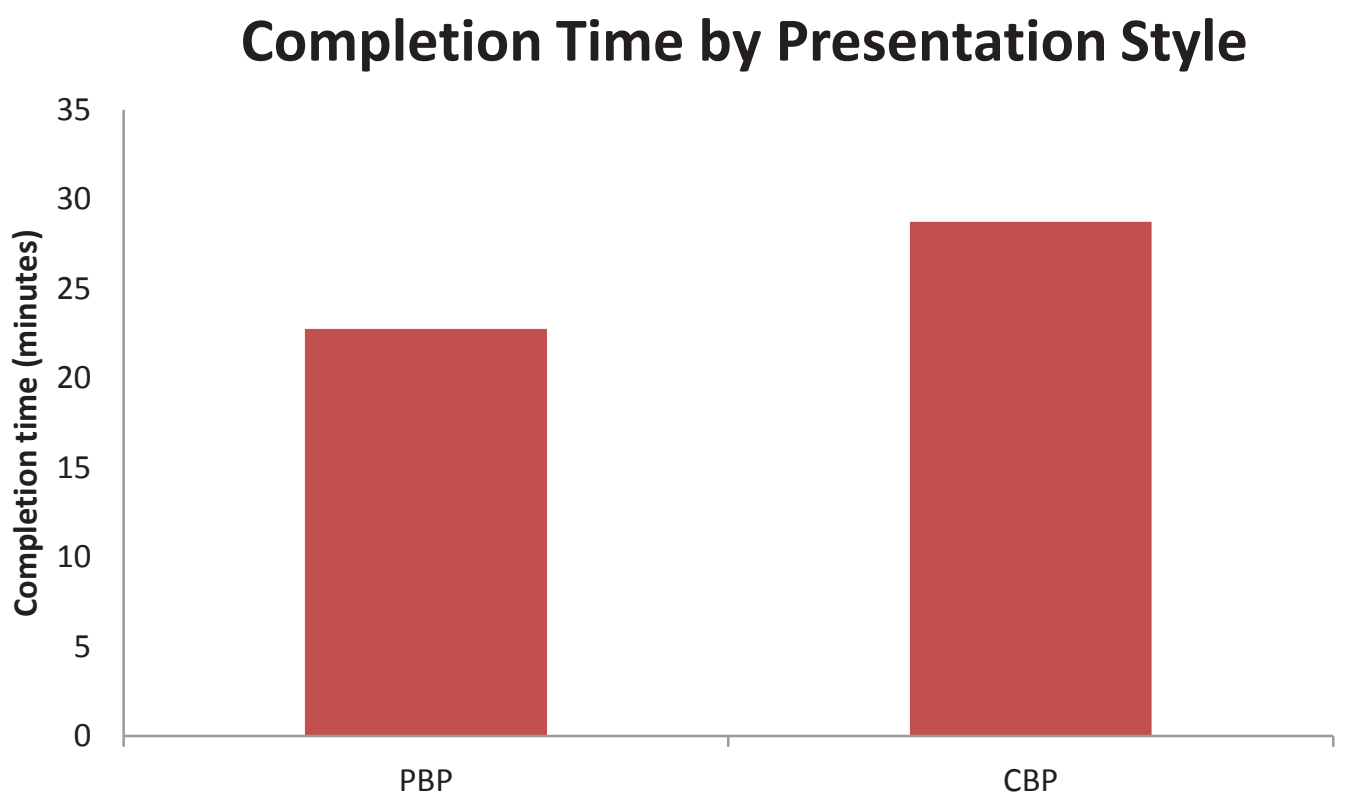

Figure 10 - Completion Time By Presentation Style

\subsubsection{Recorded Deviations}

Recorded deviations were reviewed by the research team and a trainer from the plant. Any error that did not fit straightforwardly into the predetermined coding scheme was discussed until the team came to a 
consensus as to how (and if) the error should be coded. Five recorded errors were eliminated by this process (four in the PBP condition and one in the CBP condition). Analysis of the recorded deviations was conducted using non-parametric statistical tests because the data violated the assumption of normality. A Friedman test revealed a marginally significant effect of presentation style based on type of deviation $\left(\chi_{\mathrm{f}}^{2}=7.73, \mathrm{df}=3, \mathrm{p}=.052\right)$. Planned comparisons were conducted using a Wilcoxen signedrank test. There was a marginally significant effect of presentation style on number of non-recovered deviations. There was a trend toward more non-recovered deviations in the PBP condition than the CBP condition $(Z=-1.28, p=.068)$. There was also a trend toward more recovered deviations in the CBP group than the PBP condition $(Z=-1.382, p=.1670)$. These results indicate that the CBP may be effective in preventing non-recovered errors. The fact that there is a trend toward more recovered errors in the CBP condition may be due to the operator's unfamiliarity with the interface.

There was no difference in the number of placekeeping errors based on presentation style (one was recorded for each condition). Researchers assumed that it was not possible for to make a placekeeping error in the CBP, however one participant unintentionally marked a step as complete when using the CBP. He notice the error immediately and conducted the step, however it is important to point out that even with automatic placekeeping, it is still possible to make an error.

\section{Number of Recorded Errors by Presentation Style}

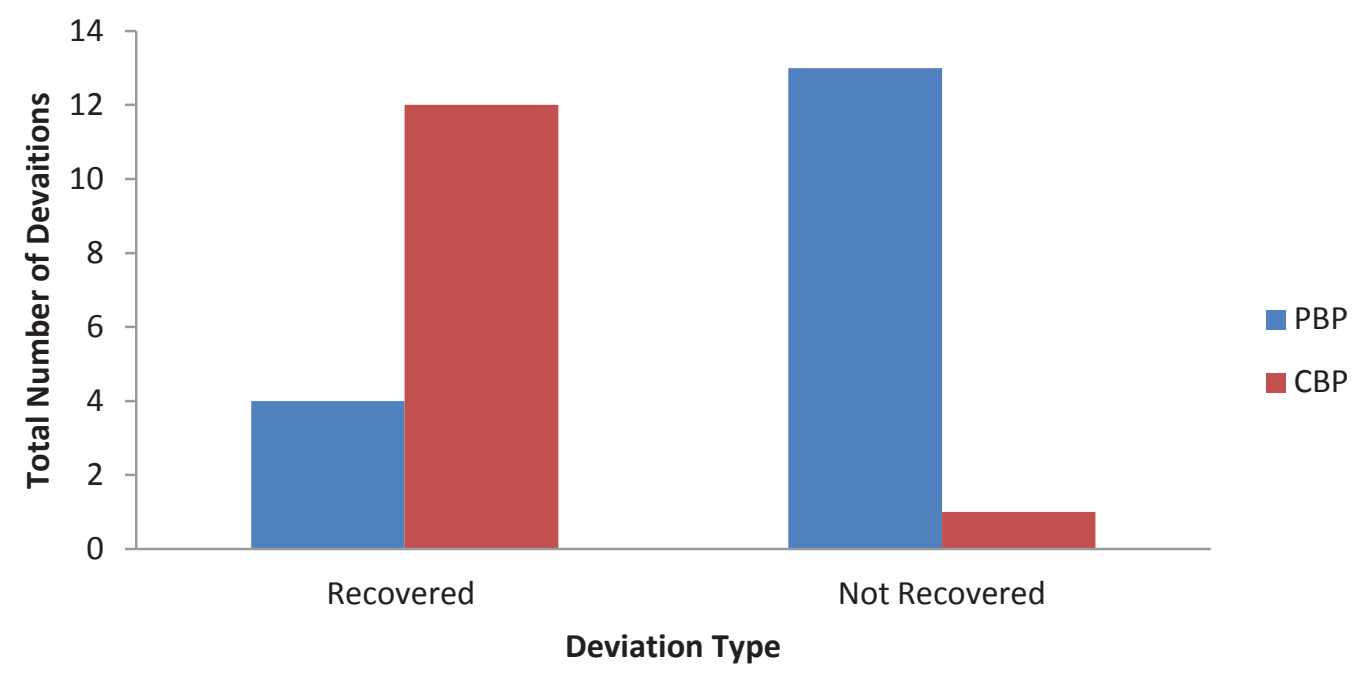

Figure 11 - Number Of Recorded Errors By Presentation Style

\subsubsection{Subjective Assessment}

\subsubsection{Usability}

Participants generally found both the device and the interface to be usable. The mean usability rating for the device was 3.9 ( $\mathrm{SD}=.68$ ) on a six-point scale. One of the specific factors that concerned operators related to the iPod was the fact that it was likely not rugged enough for work in some areas of the plant (e.g., radiation areas).. The mean usability rating of the CBP interface was $4.7(\mathrm{SD}=.69)$ on a six-point scale, indicating that the operators felt the interface was usable. 


\subsubsection{Workload Scores}

For the workload scores, the simple averages (or raw TLX scores) were computed for each condition. There were no significant differences in subjective workload between the PBP condition $(\mathrm{M}=2.15, \mathrm{SD}=$ $1)$, and the CBP condition $(\mathrm{M}=1.67, \mathrm{SD}=1)$. This indicates that the $\mathrm{CBP}$ does not increase or decrease workload compared with the PBP.

\subsubsection{Open-Ended Questions on the Debrief Questionnaire}

Before scoring the debrief questionnaire, researchers developed a coding scheme for the open-ended responses. Any responses that did not fit into the a priori coding scheme were marked as "other" during coding. The results are presented on a question-by-question basis below.

\section{Procedure Style preference}

Eighty percent of the participants preferred the CBP over the PBP. Most participants indicated that they preferred the CBP because it eliminated irrelevant steps and information and because it provided a more reliable means of correct component verification through barcode scanning. The participants that indicated they preferred the PBP, cited familiarity with the PBP process as the reason for preferring the CBP. This indicates that given a usable interface, even those performers who are resistant to switching to CBPs may shift their preference as the using the CBP becomes more familiar. These results highlight the fact that context-sensitivity is one of the more desirable advancements that can be achieved with CBPs.

\section{Context-Sensitivity}

Participants unanimously preferred the context-sensitive CBP presentation compared to the static PBP presentation. Most operators indicated that only being presented the steps relevant to the current task and conditions greatly streamlined the process, and prevented them from spending time and effort evaluating which conditions were relevant while they were out in the field.

\section{Technology as a Distraction}

Most participants (70\%) reported that they did not feel using the CBP distracted them from completing the procedural task. However, many participants reported informally that scanning the barcodes did sometimes make them feel that the task was barcode scanning and not actually executing the actions in the procedure. Another participant reported that having the logical path laid out for them made it felt like a "cookbook" approach, and that evaluating the relevant condition themselves may keep them more engaged in the tasks. The researchers will consider ways modify the prototype to help keep focus on the procedure rather than on interacting with the CBP.

\section{Usability Suggestions}

Most of the specific usability suggestion entered around improving the barcode scanning capability. Though, there were a few suggestions related to adding functionality the researchers were already planning to incorporate into future prototypes (e.g., including the ability for multiple performers to use the same CBP). The following specific suggestions are related to barcode scanning.

- Some steps need to be executed in quick succession, so it is not feasible to scan barcodes during step execution. You should either be able to scan all of the relevant barcodes before you start that sequence, or not be required to scan barcodes.

- Sometimes it acceptable to verify a component from a distance (particularly in radiation areas). Before a procedure is converted to CBP, a qualified person should complete a walk down to ensure that it makes sense to require a barcode to be scanned. 
- Provide a clear indication as to which equipment is being verified in a particular step, so the operator knows which barcode to scan. ${ }^{\mathrm{b}}$

- The steps that are not part of the selected procedure path should be available to the operator, but they should not be presented as a default. The operator should only see this information if they desire to, including it may lead to confusion and takes up unnecessary space.

\subsubsection{Comparisons with Previous Studies}

One of the goals of this effort is to provide justifiable guidance to designers of CBP systems through iterative design and evaluation. We have tested two successive versions of the CBP prototype, and though the evaluations were conducted in different settings with different samples, comparing them may help to indicate whether the CBP interface has been improved. The researchers analyzed several of the subjective factors to determine if there was an improvement between the first $\mathrm{CBP}$ and the second $\mathrm{CBP}$ prototype.

The demographics of the participants between the two studies (Study 1 and Study 2) did not vary significantly; however a greater proportion of participants responded that they preferred the CBP in study $2(80 \%)$ than in Study 1 (54\%). This may indicate that the CBP interface was more usable in the second study than in the first.

Additionally, the participants in the second study rated the usability of the interface significantly higher than those in the first study (Mean of study $1=4.7$, Mean of study $2=3.5$ ), $\mathrm{t}(19)=-.3607, \mathrm{p}=$ .002.), providing further evidence that the usability of the interface improved with the second iteration.

Both of these results indicate that the modification to the user interface and the enhanced functionality bring the CBP prototype closer to optimal for enhancing procedure execution.

\footnotetext{
${ }^{\mathrm{b}}$ Interestingly, this problem was an issue with the clarity of the step presentation, not necessarily the CBP, so this is also an issue for PBPs. However, addressing this in CBPs will help to improve the overall clarity of the procedure whatever the presentation medium.
} 


\section{General Discussion and Conclusions}

The results of this study indicate that CBPs may be effective in enhancing human performance. There were fewer overall deviations when the procedure was executed using the CBP than with the PBP. Though there were more recovered deviations with the CBPs, there were a greater number of nonrecovered deviations when the procedure was executed using the PBP. These findings show that the CBP may help operators to catch potential errors and prevent them. The most common recovered error was approaching the wrong equipment or the wrong location. The CBP required operators to scan the barcode on the equipment before they took any action, and thus provided a salient cue if they were at the wrong equipment. Therefore, the potential deviations were easily recovered from with the CBP.

The most common non-recovered deviation in the scenario occurred when operators were using a type of controller that most of them were unfamiliar with. Though all the participants had received training on this controller, many of them had not used one since that training. The deviation occurred when the operators were required to verify a tank level at another location. Many operators mistakenly believed that the level indicated on the controller was the tank level they needed to verify. However, the controller was simply displaying the set- point, not the actual level. Therefore in many cases, the performers failed to verify the tank level. The CBP required the operator to scan the barcode on the tank, and the operator was warned that he was e viewing the wrong component if he scanned the controller. Therefore the CBP prevented the deviation. Though not evaluated in this study, this situation is optimal for providing just-in-time training through the CBP interface. Perhaps embedding a brief tutorial on how to use the unfamiliar controller would have helped prevent this type of deviation. .

Though the CBP may be effective in preventing errors, it appears that it may be a tradeoff between reduction of errors and time to complete the task. In this study it took an average of six minutes longer to perform the task with the CBP than the PBP. This is consistent with the previous study which also showed a time advantage with the PBP. It is possible that the slower completion times are simply a result of being unfamiliar with conducting procedures with CBPs. However, it may be the case that there is an enduring effect on completion times, even when operators are familiar with using the CBPs. In that case, utilities will have to weigh whether reduced errors are worth the extra time it takes to execute procedures with CBPs.

The results of this study also indicate that operators are highly likely to readily accept CBPs. The majority of participants reported that they preferred the CBP over PBPs, they rated the CBP as highly usable and the unanimously preferred the dynamic context-sensitivity of CBPs to static PBPs.

Throughout the development of the CBP prototype, the researchers have approached the concept of context-sensitivity with caution. During the qualitative study and the first evaluation study, several operators indicated that they were uncomfortable with the CBP "making decisions." However, in both evaluation studies, operators indicated that they preferred to be shown only the relevant steps. The current CBP prototype appears to on capitalize on the capabilities of digital systems while providing operators access to information to ensure that the system is making the right decisions. This highlights the importance of focusing on user-centered design for CBPs.

One potential limitation to this evaluation study is that it was conducted in a training facility, not in the actual plant. Furthermore, due to an equipment malfunction in the flow loop facility, a portion of the procedure had to be simulated (for both the CBP and PBP execution). Thus the simulated nature of the task may have resulted in the operators performing differently than they would in the plant. However, both formal and informal feedback from the operators indicates that simulating tasks is something they routinely do for training purposes, and that they regard it as representative of the types of tasks they do every day. One hundred percent of participants responded that the task they executed with the CBP (and the PBP) as part of the evaluation study was realistic and representative of the tasks they do on-the-job. 
Finally, the researchers identified several areas for further improvement of the CBP prototype. The researchers will incorporate these into the next revision of the prototype. Similar to the redesign effort conducted for the study described in this report, the CBP interface will be revised to address the identified areas for improvements as well as incorporate additional functionality that previous versions did not include. These improvements will be validated in a final study that will be conducted in the spring 2013. The main research questions to be addressed in the final study are;

1. Have the modifications to the $\mathrm{CBP}$ prototype resulted in a more useable CBP interface?

2. Does the CBP prototype have the potential to improve performance over paper-based procedures?

The research team will compare the results of all three evaluation studies in terms of usability, performance time, and deviations. During the final study the researchers will also identify any additional concerns that remain to be addressed as well as reasonable solutions to these concerns.

The results of the three studies will be synthesized to provide guidance on how to effectively design the user interface of a CBP system for field operators. This guidance will also address what implications the human factors specifications have for the underlying data structure and the procedure content. 


\section{References}

Hart, S. G. \& Staveland, L. E. (1988). Development of NASA-TLX (Task Load Index): Results of empirical and theoretical research. In P. A. Hancock and N. Meshkati (eds), Human Mental Workload (Elsevier, Amsterdam), 139-183.

Le Blanc, K. and Oxstrand, J. (2012). Requirements for Computer-Based Procedures for Nuclear Power Plant Field Operators - Results from a Qualitative Study. Proceedings of 3rd International Conference on NPP Life Management for Long Term Operations (IAEA PLiM 2012). Salt Lake City, USA.

O’Hara, J. M., Brown, S. W., Lewis, P. M., and Persensky, J. J. (2002). The Effects of Interface Management Tasks on Crew Performance and Safety in Complex, Computer-Based Systems: Detailed Analysis, NUREG-CR/6690 V2, U.S. Nuclear Regulatory Commission.

Oxstrand, J.H, \& Le Blanc, K. L. (2012). Computer-Based Procedures for Field Workers in Nuclear Power Plants: Development of a Model of Procedure Usage and Identification of Requirements. Idaho National Laboratory External Report. INL/EXT-12-25671, Rev. 0.

Oxstrand, J. H, Le Blanc, K. L., and Hays, S. M. (2012). Evaluation of Computer-Based Procedure System Prototype. Idaho National Laboratory External Report.INL/EXT-12-27155, Rev. 0. 


\section{Appendix A: Task Flow Characteristics}




\begin{tabular}{|c|c|}
\hline Task Flow Characteristics & Description \\
\hline Action step & $\begin{array}{l}\text { An instruction written in active voice that directs the user to perform } \\
\text { an action and contains an action verb and an object. }\end{array}$ \\
\hline Action verb & $\begin{array}{l}\text { A verb that directs the action within a step to be taken by the } \\
\text { performer. }\end{array}$ \\
\hline Conditional step & $\begin{array}{l}\text { An action step based on plant condition or combination of conditions } \\
\text { to be satisfied prior to the performance of an action. }\end{array}$ \\
\hline Time dependant steps & A step to be completed within a specified time frame. \\
\hline Continuously applicable steps & $\begin{array}{l}\text { A step that is applicable over a period of time and requires periodic } \\
\text { monitoring until a specific condition is met. }\end{array}$ \\
\hline Multiple Action Steps & $\begin{array}{l}\text { Contain actions that are functionally related and have to be } \\
\text { performed simultaneously to obtain a single result. }\end{array}$ \\
\hline Concurrent verification & $\begin{array}{l}\text { A series of actions by two individuals working together at the same } \\
\text { time and place to separately confirm the condition of a component } \\
\text { before, during, and after an action, when the consequences of an } \\
\text { incorrect action would lead to immediate and possibly irreversible } \\
\text { harm to the plant or personnel }\end{array}$ \\
\hline Independent verification & $\begin{array}{l}\text { A series of actions by two individuals working independently to } \\
\text { confirm the condition of a component after the original act that } \\
\text { placed it in that condition }\end{array}$ \\
\hline Placekeeping & $\begin{array}{l}\text { The process used to help users track performance of steps within a } \\
\text { procedure by physically marking steps in a procedure that have been } \\
\text { completed or are not applicable. }\end{array}$ \\
\hline Notes & $\begin{array}{l}\text { Statements that provide explanatory information to support a } \\
\text { procedure step or series of steps. }\end{array}$ \\
\hline Cautions & $\begin{array}{l}\text { A statement placed immediately before applicable step(s) that } \\
\text { informs users of undesirable equipment results such as potential for } \\
\text { equipment damage, plant transients, or conditions that may } \\
\text { adversely affect plant operation. }\end{array}$ \\
\hline Warnings & $\begin{array}{l}\text { A statement placed immediately before applicable step(s) to warn } \\
\text { users of potential for personnel injury, loss of life, or health hazards. }\end{array}$ \\
\hline Supplemental information & $\begin{array}{l}\text { Procedure content that supports a procedure step or series of steps } \\
\text { and provides explanatory information. }\end{array}$ \\
\hline Attachments & $\begin{array}{l}\text { Information separated from the main body of the procedure used in } \\
\text { the performance or understanding of a procedure such as graphs, } \\
\text { figures, tables, sketches, and forms. Appendices and enclosures are } \\
\text { equivalent terms. }\end{array}$ \\
\hline Hierarchical Step Structure & $\begin{array}{l}\text { Step numbering schemes should differentiate between steps and } \\
\text { substeps of the procedure by providing identifiable differences from } \\
\text { one level or step level to the next. }\end{array}$ \\
\hline Bulleted steps & $\begin{array}{l}\text { Bulleted steps within a single step may be performed in any order and } \\
\text { shall be completed prior to proceeding to next step. }\end{array}$ \\
\hline Hold points & $\begin{array}{l}\text { A pre-selected step in a procedure that identifies a point beyond } \\
\text { which work may not proceed until the required action is performed. }\end{array}$ \\
\hline Branching steps & $\begin{array}{l}\text { A step that directs the user to other steps or sections in the same or } \\
\text { another procedure and the user does not return to the original step. }\end{array}$ \\
\hline
\end{tabular}




\begin{tabular}{|l|l|}
\hline Procedure specific information & $\begin{array}{r}\text { For example: } \\
\text { Procedure title, procedure number, revision number, level of } \\
\text { use }\end{array}$ \\
& $\begin{array}{l}\text { Purpose and scope, precautions and limitations, definitions, } \\
\text { and precautions and initial conditions }\end{array}$ \\
\hline Peer checks & $\begin{array}{l}\text { Peer-checking allows another individual to observe or check the work } \\
\text { of a performer to ensure correct performance of a specific set of } \\
\text { actions. }\end{array}$ \\
\hline
\end{tabular}


Appendix B: Demographic Survey 


\section{Computer Based Procedures: Demographic Questionnaire}

1. What is your age (in years)?

2. What is your role in the plant (i.e., your job title)?

3. How long have you been in your current role?

4. How many years have you been working in the nuclear industry?

5. Please list any previous roles you have had at a nuclear power plant (or other nuclear facility).

6. Do you use paper procedures as a part of your daily job duties?

7. Do you use any mobile electronic devices as a part of your daily job duties (e.g., personal digital assistants or tablets)? If yes, please briefly describe the device and how you use it.

8. How would you rate your experience with technology (e.g., computers, smart phones, tablets, etc.)?

$\begin{array}{llllllr}0 & 1 & 2 & 3 & 4 & 5 & 6 \\ \text { Novice } & & & & & & \text { Expert }\end{array}$


Appendix C: NASA TLX 


\section{Computer-Based Procedure Project - NASA TLX}

To be administered after each task

For each of the categories below, please draw a line indicating where on the scale you think the task falls. For example if you thought mental demand on this task was medium, you would draw a line as close to the center as you could. When evaluating each category, compare the task to driving a car in no traffic versus driving a car in heavy traffic.

Mental Demand -- How much mental activity was required (e.g., thinking, deciding, calculating, remembering, looking, searching, etc.)? Was the task easy or demanding, simple or complex, exacting or forgiving?

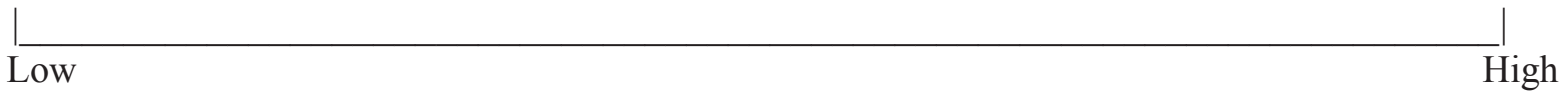

Physical Demand - How much physical activity was required (e.g., pushing, pulling, turning, controlling, activating, etc.) Was the task easy or demanding, slow or brisk, slack or strenuous, restful or laborious?

Low

High

Temporal Demand - How much time pressure did you feel due to the rate or pace at which the task or task elements occurred? Was the pace slow and leisurely or rapid and frantic?

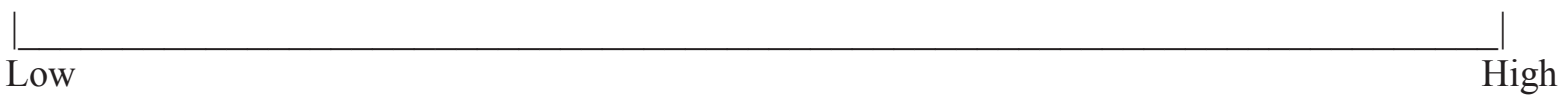

Performance - How successful do you think you were in accomplishing the goals of the task set by the experimenter (or yourself)? How satisfied were you with your performance in accomplishing these goals?

Good Poor


Effort - How hard did you have to work (mentally and physically) to accomplish your level of performance?

Low High

Frustration Level - How insecure, discouraged, irritated, stressed, and annoyed versus secure, gratified, content, relaxed, and complacent did you feel during the task?

Low High


Appendix D: Usability Survey 


\section{Computer-Based Procedures: Usability Survey}

To be administered only after the CBP task

\section{Device}

Please rate the suitability of the device (i.e., the iPod) for the task you did today based on the following factors. Circle the number that best applies.

1. Size

$\begin{array}{llllllr}0 & 1 & 2 & 3 & 4 & 5 & 6 \\ \text { Inadequate } & & & & \text { Adequate }\end{array}$

2. Weight

$\begin{array}{llllllr}0 & 1 & 2 & 3 & 4 & 5 & 6 \\ \text { Inadequate } & & & & \text { Adequate }\end{array}$

3. Screen Size

$\begin{array}{llllllr}0 & 1 & 2 & 3 & 4 & 5 & 6 \\ \text { Inadequate } & & & & \text { Adequate }\end{array}$

4. Display Brightness

$\begin{array}{lllllll}0 & 1 & 2 & 3 & 4 & 5 & 6\end{array}$

5. Ruggedness

$\begin{array}{llllllr}0 & 1 & 2 & 3 & 4 & 5 & 6 \\ \text { Inadequate } & & & & \text { Adequate }\end{array}$

6. Would any of the responses to the above be different for the tasks you do in your normal job duties (as opposed to the task you did today)? Please explain.

\section{Interface}

Please rate the computer-based procedure software based on the following. Circle the number that best applies.

1. It was easy to navigate to the screen that I needed.

$\begin{array}{lrrrrcc}0 & 1 & 2 & 3 & 4 & 5 & 6 \\ \text { Strongly Disagree } & & & & \text { Strongly Agree }\end{array}$


2. I understood how to use the software to complete the task.

$\begin{array}{lrrrrcc}0 & 1 & 2 & 3 & 4 & 5 & 6 \\ \text { Strongly Disagree } & & & & \text { Strongly Agree }\end{array}$

3. I was able to find the information I needed easily.

$\begin{array}{lrrrrcc}0 & 1 & 2 & 3 & 4 & 5 & 6 \\ \text { Strongly Disagree } & & & & \text { Strongly Agree }\end{array}$

4. I sometimes got lost, and could not find the screen I needed. (reverse scored)

$\begin{array}{lrrrrcc}0 & 1 & 2 & 3 & 4 & 5 & 6 \\ \text { Strongly Disagree } & & & & \text { Strongly Agree }\end{array}$

5. The interface behaved exactly as I expected it to.

$\begin{array}{lrrrrcc}0 & 1 & 2 & 3 & 4 & 5 & 6 \\ \text { Strongly Disagree } & & & & \text { Strongly Agree }\end{array}$

6. I was sometimes confused about where I was in the procedure. (reverse scored)

$\begin{array}{lrrrrcc}0 & 1 & 2 & 3 & 4 & 5 & 6 \\ \text { Strongly Disagree } & & & & \text { Strongly Agree }\end{array}$

7. It was easy to undo something if I made a mistake.

$\begin{array}{lrrrrcc}0 & 1 & 2 & 3 & 4 & 5 & 6 \\ \text { Strongly Disagree } & & & & \text { Strongly Agree }\end{array}$

8. I was sometimes surprised by how the computer-based procedure system responded. (reverse scored)

$\begin{array}{lrrrrcc}0 & 1 & 2 & 3 & 4 & 5 & 6 \\ \text { Strongly Disagree } & & & & \text { Strongly Agree }\end{array}$




\section{Appendix E: Debriefing Questionnaire}




\section{Computer-Based Procedures: Debrief Questionnaire}

1. Now that you have executed the procedure using both the paper-based procedure and the computer-based procedure, which did you prefer?

Why?

2. The computer-based procedure presented only the steps that were relevant under the current conditions; did you find it confusing to not see the irrelevant steps?

3. Do you feel that using the technology distracted you from your primary task (i.e., executing the procedure)?

4. Do you have any suggestions for how to improve the user interface?

5. Was the task you completed today representative of the tasks you would complete as part of your normal job duties?

6. Did you find the scenario you completed today to be realistic? Why or why not?

7. Is there anything you would like to add? 


\section{Appendix F: The Procedure}




\section{Objective}

To describe the procedure for operating the Training Flow Loop.

\section{Limits and Precautions}

2.1 Do NOT allow the glycol solution to be spilled into the environment.

2.2 When venting, all vents should be routed to a container.

2.3 When manually operating any motor operated valve, minimize the torque applied to the handwheel.

2.411 Glycol is a serious health hazard. Avoid skin contact and inhalation of vapors. Refer to MSDS \#0645.

\section{Enclosures}

3.1 Flow Loop Cold Water System Start-Up

3.2 Flow Loop Control loop system Start-Up

3.3 Flow Loop Valve Checklist 


\section{Flow Loop Cold Water System Start-up \\ Enclosure 3.1}

$\mathrm{OP} / \mathbf{0} / \mathrm{A} / 6400 / 014 \mathrm{INL}$

\section{Initial Conditions}

1.1 Review the Limits and Precautions.

1.2 Verify that the Chemistry portion of the Flow Loop System is in service per OP/0/B/6400/007

(Flow Loop Makeup).

Chemistry Contact

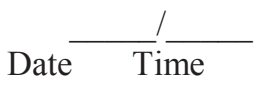

\section{Procedure}

2.1 Ensure valves are aligned per Enclosure 4.3:

2.2 Verify TCW-TK (Cold Water Storage Tank) level is $>100 "$ as indicated on TCW-LG 5000

(Cold Water Storage Tank Level) (TF-594', Fa-4a)

2.3 Open TCW-010 (Cold Water Storage Tank Outlet Isol) (TF-594', Fa-4)

2.4 IF starting TCW-PU A (Cold Water Pump A) (F-594', E-4) perform the following

2.4.1 Place the key (8, or 9) in switch TCW-PU A (T-MC1)

2.4.2 Rotate the key switch TCW-PU A to the "AUTO" position

2.4.3 Unlock and throttle TCW-013 (Cold Water Pump A Disch Throttle) (TTF 594', Ec-4a)) to obtain 50-60\% on TCW-P5010 (Cold Water Pump A Disch Flow) (TMC-1) (TTF 594', Ec-5)

2.5 IF starting TCW-PU B Cold Water pump B perform the following

2.5.1 Place the key (8, or 9) in switch TCW-PU B (T-MC1)

2.5.2 Rotate the key switch TCW-PU B to the "AUTO" position

2.5.3 Unlock and throttle TCW-016 (Cold Water Pump B Disch Throttle) (TTF 594', Ec-4a)) to obtain 50-60\% on TCW-P5020 (Cold Water Pump B Disch Flow) (TMC-1) (TTF 594', Ec-4a)

2.6 IF started on step 2.4 record TCW-PU A (Cold Water Pump A) data as follows.

- TCW PG 5010 Cold Water Pump A Suction Pressure psig

- $\quad$ TCW PG 5020 Cold Water Pump A Disch Pressure psig

- TCW P 5010 Cold Water Pump A Disch Flow $\%$

- $\quad$ TCW P 5000 TCW-PU A from T-TBOX0907 ammeter amps 


\section{Flow Loop Cold Water System Start-up \\ Enclosure 3.1}

$\mathrm{OP} / \mathbf{0} / \mathrm{A} / 6400 / 014 \mathrm{INL}$

2.7 IF started on step 2.5 record TCW-PU B Cold Water Pump B Data as Follows.

- $\quad$ TCW PG 5030 Cold Water Pump B Suction Pressure psig

- $\quad$ TCW PG 5040 Cold Water Pump B Disch Pressure psig

- $\quad$ TCW P 5020 Cold Water Pump B Disch Flow $\%$

- $\quad$ TCW P 5001 TCW-PU B from T-TBOX0907 ammeter amps

2.8 Perform visual inspection for leaks around pump

NOTE: Cold Water System is now in operation, the following steps secure the Cold Water System

2.9 IF running secure TCW-PU A Cold Water Pump A as follows

2.9.1 Rotate key switch TCW-PU A to the "OFF" position

2.9.2 Remove the Key (8, or 9) from switch TCW-PU A

2.10 IF running secure TCW-PU B Cold Water Pump B as follows

2.10.1 Rotate key switch TCW-PU B to the "OFF" position

2.10.2 Remove the Key (8, or 9) from switch TCW-PU B

2.11 Close TCW-010 (Cold Water Storage Tank Outlet Isol)

2.12 File this enclosure in the Control Copy folder of this procedure 


\section{Flow Loop Control loop system Start-Up \\ Enclosure 3.2}

$\mathrm{OP} / \mathbf{0} / \mathrm{A} / 6400 / 014 \mathrm{INL}$

\section{Initial Conditions}

1.1 Review the Limits and Precautions.

1.2 Verify Flow Loop System Cold Water System is in service per Enclosure 4.1 of this procedure.

1.3 Verify Chemistry portion of the Flow Loop System is in service per OP/0/B/6400/007 (Flow Loop Makeup).

Chemistry Contact

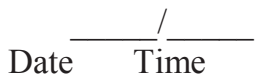

2. Procedure - SIMULATED IN BOTH PBP AND CBP CONDITIONS

2.1 Place TCL SS 5021 (Control Loop Controller) in Manual(T-MC-1).

2.2 Open TCW-010 (Cold Water Storage Tank Outlet Isol) (TF-594', Fa-4)

2.3 Ensure the Following Valves are Open:

- $\quad$ TCW-084(Cold Water Pump A Disch To Level Control Loop Isol ) (TTF 594', Ec-4a)

- $\quad$ TCW-085(Cold Water Pump B Disch To Level Control Loop Isol) (TTF 594', Ec-4a)

- TCL-010 (Control Loop Inlet Flow Isol) (TTF 594', Ec-4a)

CAUTION: (Tnk Level Ctrl) shall NOT be closed as it provides minimum flow for the TCL storage tank supply pumps when they cycle "ON" to control TCL storage tank level.

2.4 Place TCL SS 5021 in Automatic.

2.5 Start TCL Tank Discharge Pump as follows

2.5.1 Place the key (8, or 9) in switch TCL-P5000 (T-MC1)

2.5.2 Rotate the key switch TCL-P5000 to the hand position

2.6 Slowly adjust SS 5021 (Control Loop Controller) to 35\%

2.7 Verify SS 5021 (Control Loop Controller) tracks and maintains TCL-TK level at 35\%

2.8 Record TCL Tank Discharge Pump Data as Follows. 


\section{Flow Loop Control loop system Start-Up \\ Enclosure 3.2}

- TCL PG 5010 Control Loop Pump Suction Pressure

- TCL PG 5020 Control Loop Pump Disch Pressure

- TCL P 5000 TCL-PU from T-TBOX0914 ammeter

2.9 Perform visual inspection for leaks around pump

2.10 Slowly adjust TCL SS 5021 (Control Loop Controller) to 25\%

2.11 Verify TCL SS 5021 (Control Loop Controller) tracks and maintains TCL-TK level at $25 \%$

2.12 Slowly adjust TCL SS 5021 (Control Loop Controller) to 30\%

2.13 Verify TCL SS 5021 (Control Loop Controller) tracks and maintains TCL-TK level at $30 \%$

2.14 Place TCL SS 5021 (Control Loop Controller) in Manual

CAUTION: The TCL Tank Discharge Pump must be returned to auto, to prevent overfill of TCL-TK in the event of valve leak by.

CAUTION: It is essential for the operator to read and understand the following steps before attempting to close valve TCL-011 from the selector station. Quick response to any changes in TCLTK level when the valve is closed is required to reduce the likelihood of a loss of NPSH to the TCL-PU. The following two steps shall be performed prior to signing off either step.

2.15 Close valve TCL-011 from selector station TCL SS 5021 (Control Loop Controller)

2.16 Secure TCL Discharge pump as follows

2.16.1 Rotate key switch TCL-PU to the "AUTO" position

2.16.2 Remove Key (8, or 9) from switch TCL-PU

2.17 File this enclosure in the Control Copy folder of this procedure 
Flow Loop Valve Checklist

OP/0/A/6400/014 INL

\section{Enclosure 3.3}

\begin{tabular}{|c|c|c|c|c|}
\hline $\begin{array}{l}\text { VALVE } \\
\text { NO. }\end{array}$ & VALVE & LOCATION & POSITION & $\begin{array}{l}\text { DATE } \\
\text { INITIAL }\end{array}$ \\
\hline TCL-017 & Control Loop Disch Flow Bypass & TTF(Dc-4a) & Closed & \\
\hline TCL-018 & Control Loop Safety/Flow Perturbation & TTF(Ea-4a) & Closed & $\begin{array}{l}-3-04 \\
\text { vEE }\end{array}$ \\
\hline TCL-019 & $\begin{array}{l}\text { Control Loop Feed Flow Manual } \\
\text { Perturbation }\end{array}$ & TTF(Ea-4a) & Closed & $\sqrt[1-3-04]{B E}$ \\
\hline TCL-020 & Duplex Strainer Inlet Isol & TTF(Cd-4a) & Open & \\
\hline TCL-021 & Duplex Strainer Outlet Isol & TTF(Da-4) & Open & \\
\hline TCL-022 & Duplex Strainer Bypass & TTF(Da-4) & Closed & \\
\hline TCL-023 & $\begin{array}{l}\text { Portable Filter/Demin Connection Inlet } \\
\text { Isol }\end{array}$ & TTF(Da-4) & Closed & \\
\hline TCL-024 & $\begin{array}{l}\text { Portable Filter/Demin Connection Outlet } \\
\text { Isol }\end{array}$ & TTF(Cd-4a) & Closed & \\
\hline TCL-026 & Control Loop Pump Disch Relief & TTF(D-4) & Installed & \\
\hline TCL-027 & $\begin{array}{l}\text { Control Loop Pump Disch Header Sample } \\
\text { Sink Root }\end{array}$ & TTF(D-4) & Open & \\
\hline TCL-028 & Control Loop Pump Suction Header Vent & TTF(D-4) & Closed/Capped & \\
\hline TCL-029 & Control Loop Tank Drain & $\mathrm{TTF}(\mathrm{Da}-4)$ & Closed/Capped & \\
\hline TCL-030 & Control Loop Pump Suction Drain & TTF(D-4)) & Closed/Capped & \\
\hline TCL-031 & Control Loop Pump Disch Drain & TTF(D-4) & Closed/Capped & \\
\hline TCL-032 & Control Loop Feed Flow Header Drain & TTF(Eb-4a) & Closed/Capped & $\sqrt[1-3-04]{B E}$ \\
\hline TCL-033 & Control Loop Perturbation Header Drain & TTF(Eb-4a) & Closed/Capped & \\
\hline TCL-034 & $\begin{array}{l}\text { Control Loop Disch Flow Inlet Header } \\
\text { Drain }\end{array}$ & TTF(Dc-4a) & Closed/Capped & \\
\hline TCW-090 & Reach Rod Station Vent & TTF(Dc-4a) & Closed/Capped & \\
\hline
\end{tabular}

